\title{
Myocarditis and inflammatory cardiomyopathy: current evidence and future directions
}

\author{
Carsten Tschöpe ${ }^{1,2,3 凶}$, Enrico Ammirati ${ }^{4}$, Biykem Bozkurt ${ }^{5,6}$, Alida L. P. Caforio (1) 7 , \\ Leslie T. Cooper, Stephan B. Felix ${ }^{9,10}$, Joshua M. Hare ${ }^{11}$, Bettina Heidecker ${ }^{12}$, \\ Stephane Heymans ${ }^{13,14}$, Norbert Hübner $\mathbb{1}^{2,15,16}$, Sebastian Kelle ${ }^{2,3,17}$, Karin Klingel ${ }^{18}$, \\ Henrike Maatz ${ }^{15}$, Abdul S. Parwani ${ }^{3}$, Frank Spillmann ${ }^{3}$, Randall C. Starling ${ }^{19}$, \\ Hiroyuki Tsutsui ${ }^{20}$, Petar Seferovic ${ }^{21}$ and Sophie Van Linthout ${ }^{1,2}$
}

Abstract | Inflammatory cardiomyopathy, characterized by inflammatory cell infiltration into the myocardium and a high risk of deteriorating cardiac function, has a heterogeneous aetiology. Inflammatory cardiomyopathy is predominantly mediated by viral infection, but can also be induced by bacterial, protozoal or fungal infections as well as a wide variety of toxic substances and drugs and systemic immune-mediated diseases. Despite extensive research, inflammatory cardiomyopathy complicated by left ventricular dysfunction, heart failure or arrhythmia is associated with a poor prognosis. At present, the reason why some patients recover without residual myocardial injury whereas others develop dilated cardiomyopathy is unclear. The relative roles of the pathogen, host genomics and environmental factors in disease progression and healing are still under discussion, including which viruses are active inducers and which are only bystanders. As a consequence, treatment strategies are not well established. In this Review, we summarize and evaluate the available evidence on the pathogenesis, diagnosis and treatment of myocarditis and inflammatory cardiomyopathy, with a special focus on virus-induced and virus-associated myocarditis. Furthermore, we identify knowledge gaps, appraise the available experimental models and propose future directions for the field. The current knowledge and open questions regarding the cardiovascular effects associated with severe acute respiratory syndrome coronavirus 2 (SARS-CoV-2) infection are also discussed. This Review is the result of scientific cooperation of members of the Heart Failure Association of the ESC, the Heart Failure Society of America and the Japanese Heart Failure Society.

Inflammatory cardiomyopathy is defined as myocarditis in association with cardiac dysfunction and ventricular remodelling ${ }^{1,2}$. Despite extensive research and improved diagnosis and understanding of the pathogenesis of inflammatory cardiomyopathy, this disorder is still associated with a poor prognosis when complicated by left ventricular (LV) dysfunction, heart failure (HF) or arrhythmia ${ }^{3}$. Furthermore, fulminant myocarditis, a rare, sudden and severe cardiac inflammation, is one of the main causes of cardiogenic shock in young adults ${ }^{4,5}$. Prompt diagnosis and specific treatment strategies are needed to reduce mortality and the need for heart transplantation in these patients ${ }^{4,5}$. Many questions remain unanswered regarding the pathogenesis of inflammatory cardiomyopathy and the role of the viral infection, the immune system, the host genetic background and the environment in disease progression and prognosis. These gaps in knowledge highlight the need for advanced experimental systems that can better model the human immune system and the need to improve the characterization and classification of the patients, for example, with the use of phenomapping and phenomics, which involve detailed evaluation of immune status, viral presence and/or other biomarkers.

In this Review, we discuss the available evidence and identify the gaps in our understanding of the pathogenesis, diagnosis, treatment and prognosis of myocarditis and inflammatory cardiomyopathy, appraise the available animal and cell models of these conditions and propose future directions for the field. We discuss the role 


\section{Key points}

- The role of specific viruses, immune cells and autoimmunity in the pathogenesis of myocarditis and inflammatory cardiomyopathy is still incompletely understood, and advanced animal and cell models are required for future research.

- Advanced animal models that take into account immune experience and exposure to environmental factors and in vitro models with immune cell interactions are needed to facilitate better clinical translation of the findings.

- Improved standardization of available invasive and noninvasive diagnostic tools and a consensus on their specific use are needed to allow specific diagnosis and stratification of patient cohorts for the implementation of aetiology-based therapies.

To develop aetiology-based therapies, the efficacy of many existing, repurposed or emerging therapies needs to be evaluated in large, controlled, randomized trials.

of viruses as active inducers or as potential bystanders of myocarditis and inflammatory cardiomyopathy. We assess the relevance of histology, immunohistology and molecular biology techniques for the analysis of endomyocardial biopsy (EMB) samples, as well as advanced imaging methods and the role of inflammatory and immune cell markers, immune cell ratios, microRNAs and antibodies for the diagnosis, guidance of therapeutic decisions and management in patients with myocarditis and inflammatory cardiomyopathy. We outline patient-specific therapeutic options that are based on an accurate diagnosis, covering current and novel strategies. The aim of the Review is to help clinicians and scientists apply the best diagnostic and therapeutic approaches to solve individual patient problems in clinical practice.

\footnotetext{
Author addresses

${ }^{1}$ Berlin Institute of Health Center for Regenerative Therapies (BCRT), Charité - University Medicine Berlin, Campus Virchow Clinic, Berlin, Germany.

${ }^{2}$ German Centre for Cardiovascular Research (DZHK), partner site Berlin, Berlin, Germany. ${ }^{3}$ Department of Cardiology, Charité - University Medicine Berlin, Campus Virchow Klinikum, Berlin, Germany.

${ }^{4}$ De Gasperis Cardio Center and Transplant Center, Niguarda Hospital, Milan, Italy. ${ }^{5}$ Winters Center for Heart Failure Research, Cardiovascular Research Institute, Baylor College of Medicine, Houston, TX, USA.

${ }^{6}$ Michael E. DeBakey VA Medical Center, Houston, Texas, USA.

${ }^{7}$ Division of Cardiology, Department of Cardiological, Thoracic and Vascular Sciences and Public Health, Centro Gallucci, University of Padova-Policlinico, Padova, Italy. ${ }^{8}$ Department of Cardiovascular Medicine, Mayo Clinic, Jacksonville, FL, USA.

${ }^{9}$ Department of Internal Medicine B, University Medicine Greifswald, Greifswald, Germany.

${ }^{10}$ German Centre for Cardiovascular Research (DZHK), partner site Greifswald, Greifswald, Germany.

${ }^{11}$ University of Miami, Miller School of Medicine, Miami, FL, USA

${ }^{12}$ Department of Cardiology, Charité - University Medicine Berlin, Campus Benjamin Franklin, Berlin, Germany.

${ }^{13}$ Department of Cardiology, CARIM, Maastricht University, Maastricht, Netherlands.

${ }^{14}$ Department of Cardiovascular Sciences, University of Leuven, Leuven, Belgium.

${ }^{15}$ Cardiovascular and Metabolic Sciences, Max Delbrück Center for Molecular Medicine in the Helmholtz Association (MDC), Berlin, Germany.

${ }^{16}$ Berlin Institute of Health (BIH), Charité - University Medicine Berlin, Berlin, Germany.

${ }^{17}$ Department of Internal Medicine/Cardiology, German Heart Center Berlin, Berlin,

Germany.

${ }^{18}$ Cardiopathology, Institute for Pathology and Neuropathology, University Hospital

Tübingen, Tübingen, Germany.

${ }^{19}$ Kaufman Center for Heart Failure, Department of Cardiovascular Medicine, Cleveland Clinic, Cleveland, OH, USA.

${ }^{20}$ Department of Cardiovascular Medicine, Faculty of Medical Sciences, Kyushu University, Fukuoka, Japan.

${ }^{21}$ Faculty of Medicine, University of Belgrade, Belgrade, Serbia.
}

This Review is the result of a scientific cooperation of members from the Heart Failure Association of the ESC, the Heart Failure Society of America and the Japanese Heart Failure Society.

\section{Pathogenesis \\ The role of viruses}

Myocarditis is an inflammatory cardiac disorder induced predominantly by viruses ${ }^{6,7}$ but also by other infectious agents including bacteria (such as Borrelia spp.), protozoa (such as Trypanosoma cruzi) and fungi. Myocarditis can also be induced by a wide variety of toxic substances and drugs (such as immune checkpoint inhibitors) ${ }^{8}$ and systemic immune-mediated diseases ${ }^{9}$. Importantly, the aetiopathogenesis, induction and course of myocarditis related to different infectious agents vary considerably. The most common viruses associated with inflammatory cardiomyopathy include: primary cardiotropic viruses that can be cleared from the heart, including adenoviruses and enteroviruses (such as coxsackie A viruses or coxsackie B viruses, and echoviruses); vasculotropic viruses that are likely to have lifelong persistence, including parvovirus B19 (B19V; from the erythrovirus family); lymphotropic viruses with lifelong persistence that belong to the Herpesviridae family (such as human herpesvirus 6 (HHV6), Epstein-Barr virus and human cytomegalovirus); viruses that indirectly trigger myocarditis by activating the immune system ${ }^{10,11}$, including human immunodeficiency virus (HIV), hepatitis $\mathrm{C}$ virus (HCV), influenza $\mathrm{A}$ virus and influenza $B$ virus; and viruses from the Coronaviridae family, including Middle East respiratory syndrome coronavirus (MERS-CoV), severe acute respiratory syndrome coronavirus (SARS-CoV) and SARS-CoV-2, which have angiotensin-converting enzyme 2 (ACE2) tropism and can potentially mediate direct cardiac injury. These coronaviruses are also suggested to indirectly trigger myocarditis, in a similar manner to influenza A and $B$ viruses, via cytokine-mediated cardiotoxicity or by triggering an autoimmune response against components of the heart ${ }^{12}$ (TABLE 1). The exact pathological mechanisms underlying SARS-CoV-2-associated heart disease are so far unknown and require in-depth investigation of EMB and autopsy samples from affected patients.

A distinction is needed between virus-induced inflammatory cardiomyopathy and virus-associated inflammatory cardiomyopathy (in case of viral latency), which depends on the causality between the virus and the pathogenesis of inflammatory cardiomyopathy. Furthermore, a clear classification should be made to distinguish between viruses that directly (cardiotropic and vasculotropic viruses) or indirectly (lymphotropic viruses) infiltrate the heart, and viruses that might not necessarily infect cardiac cells but indirectly induce cardiac injury and negative inotropy by triggering a cytokine storm or a cellular immune response by molecular mimicry.

The ESC guidelines require viral diagnostics ${ }^{2}$, involving viral genome analysis of EMB samples via quantitative PCR, to define the underlying aetiology of inflammatory cardiomyopathy. By contrast, the AHA does not recommend routine viral genome analysis for 
Table 1 | Viruses associated with myocarditis and inflammatory cardiomyopathy

\begin{tabular}{|c|c|c|c|c|}
\hline Viral tropism & Virus & $\begin{array}{l}\text { Viral } \\
\text { genome }\end{array}$ & Virulence & $\begin{array}{l}\text { Treatment for associated heart } \\
\text { disease }\end{array}$ \\
\hline \multirow[t]{2}{*}{ Cardiotropic } & Adenoviruses & dsDNA & \multirow[t]{2}{*}{ Virulent } & \multirow{2}{*}{$\begin{array}{l}\text { IFNa or IFN } \beta \text { (?); direct-acting } \\
\text { antiviral therapy (?); intravenous } \\
\text { immunoglobulins (?) }\end{array}$} \\
\hline & $\begin{array}{l}\text { Enteroviruses } \\
\text { (coxsackieviruses, } \\
\text { echoviruses) }\end{array}$ & $(+)$ ssRNA & & \\
\hline \multirow[t]{2}{*}{ Vasculotropic } & \multirow[t]{2}{*}{ Parvovirus B19 } & \multirow[t]{2}{*}{ ssDNA } & $\begin{array}{l}\text { Bystander: latent; low viral } \\
\text { DNA copy numbers in cardiac } \\
\text { tissue; with or without cardiac } \\
\text { inflammation }\end{array}$ & No need for antiviral therapy \\
\hline & & & $\begin{array}{l}\text { Virulent: high viral DNA copy } \\
\text { numbers in cardiac tissue } \\
(>500 \text { viral DNA copies per micro- } \\
\text { gram cardiac DNA) with cardiac } \\
\text { inflammation or systemic infection }\end{array}$ & $\begin{array}{l}\text { Intravenous injection of } \\
\text { immunoglobulins (?) }\end{array}$ \\
\hline \multirow[t]{2}{*}{ Lymphotropic } & \multirow{2}{*}{$\begin{array}{l}\text { Cytomegalovirus; } \\
\text { Epstein-Barr } \\
\text { virus; human } \\
\text { herpesvirus } 6\end{array}$} & \multirow[t]{2}{*}{ dsDNA } & $\begin{array}{l}\text { Bystander: latent; low DNA copy } \\
\text { numbers in cardiac tissue; with or } \\
\text { without cardiac inflammation }\end{array}$ & No need for antiviral therapy \\
\hline & & & $\begin{array}{l}\text { Virulent: high cardiac DNA } \\
\text { copy numbers; with cardiac } \\
\text { inflammation }\end{array}$ & Anti-herpesvirus drugs \\
\hline Cardiotoxic & $\begin{array}{l}\text { Hepatitis C virus; } \\
\text { HIV; Influenza } \\
\text { viruses }\end{array}$ & $(+)$ ssRNA & $\begin{array}{l}\text { Virulent: cardiac inflammation } \\
\text { with viraemia }\end{array}$ & Direct-acting antiviral therapy \\
\hline $\begin{array}{l}\text { ACE2-tropic; } \\
\text { cardiotoxic (?) }\end{array}$ & $\begin{array}{l}\text { Coronaviruses } \\
\text { (MERS-CoV, } \\
\text { SARS-CoV, } \\
\text { SARS-CoV-2) }\end{array}$ & $(+)$ ssRNA & $\begin{array}{l}\text { Virulent: viraemia; cardiac } \\
\text { inflammation (?) }\end{array}$ & $\begin{array}{l}\text { Potential treatments currently } \\
\text { under investigation: remdesivir; } \\
\text { hydroxychloroquine and azithro- } \\
\text { mycin; darunavir and cobicistat; } \\
\text { lopinavir-ritonavir; favipiravir; } \\
\text { ribavirin; IFNa; camostat mesylate }\end{array}$ \\
\hline
\end{tabular}

the diagnosis of (viral) inflammatory cardiomyopathy ${ }^{13}$, but this technique is discussed in a 2020 scientific statement as a potential option in cases of diagnostic uncertainty ${ }^{4}$. Further prospective studies are needed to determine and validate the role of viral genome detection in the heart in the diagnosis and management of inflammatory cardiomyopathy.

In the past two decades, B19V and HHV6 have been more frequently detected in EMB samples from patients with myocarditis than enteroviruses or adenoviruses, and approximately $30 \%$ of patients have multiple viral infections ${ }^{10,14}$. In infants, a high number of cases of acute enterovirus myocarditis has been observed in the past 5 years ${ }^{15-17}$. In general, the detection frequency of the viruses associated with inflammatory cardiomyopathy has changed over time, partly influenced by the evaluation of a broader repertoire of viruses (FIG. 1). Many viral infections have a characteristic seasonal distribution. For example, influenza viruses are prevalent during the winter months, whereas enteroviruses, including coxsackie A and B viruses, and echoviruses, are more frequently detected during summer and autumn ${ }^{18}$. However, regional climate differences can influence the seasonal variation of viral infections ${ }^{18}$. Enteroviral myocarditis predominates in male adolescent and adult patients ${ }^{19}$. Male sex is also a major risk factor for death in patients with coronavirus disease 2019 (COVID-19), which is caused by SARS-CoV-2 infection ${ }^{20}$, suggesting that the outcome of virus-associated heart disease might depend on differences in the immune responses between women and men ${ }^{21,22}$.

Adenoviruses and enteroviruses. Enteroviruses, most commonly coxsackie B viruses, and some adenoviruses are established causes of acute myocarditis and inflammatory cardiomyopathy ${ }^{18}$. These viruses infect cardiomyocytes by binding to a common transmembrane receptor (the coxsackievirus and adenovirus receptor $\left.(\mathrm{CAR})^{23}\right)$ and can thereby induce direct myocardial injury, including cytoskeletal disruption ${ }^{24}$, and trigger an uncontrolled immune response even after viral clearance. These viruses are examples of cytolytic viruses, which trigger myocarditis by inducing viral replication inside the host cell followed by lysis of the cell for viral release. Persistence of adenoviruses and enteroviruses in the myocardium leads to LV dysfunction, poor clinical outcomes and increased mortality in these patients ${ }^{10,25}$. However, about $50 \%$ of patients with enterovirusinduced or adenovirus-induced myocarditis completely recover without residual injuries, resulting in healed myocarditis ${ }^{26}$. Patients carrying the CCR $5 \Delta 32$ deletion (which results in deficiency of CC-chemokine receptor 5 (CCR5)), either in heterozygosity or homozygosity, showed spontaneous clearance of enterovirus infection compared with patients carrying the wild-type CCR5 (REF. ${ }^{25}$ ), a finding that accentuates the importance 


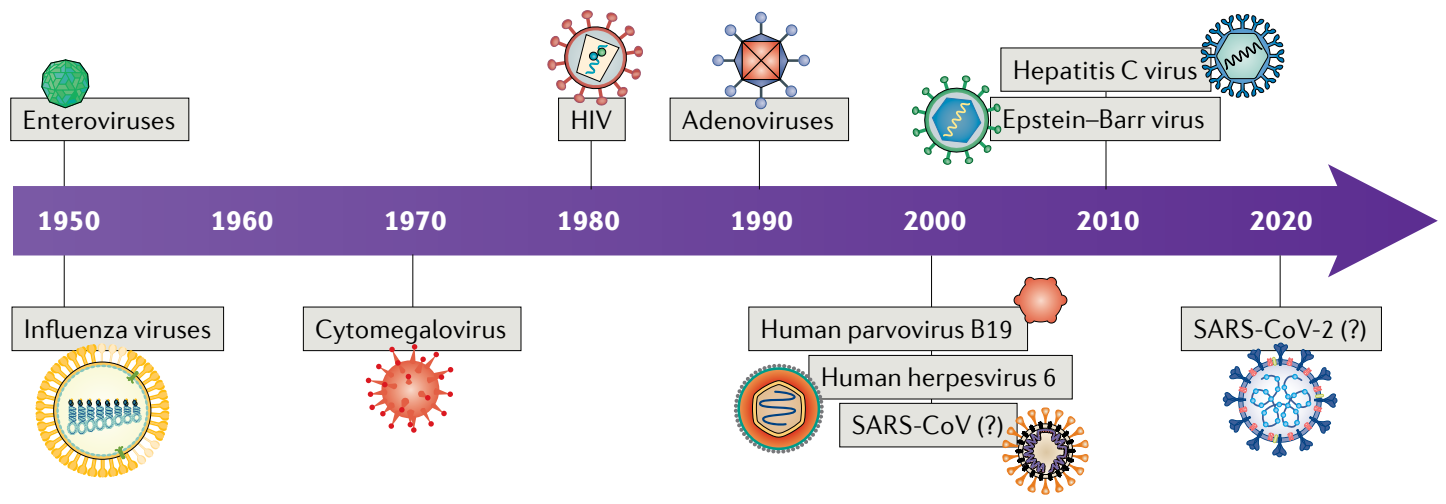

Fig. 1 | Prominent viruses associated with inflammatory cardiomyopathy over time. Over the years, the number of recognized viruses associated with inflammatory cardiomyopathy has grown. This evolution is partly influenced by the intentional detection of a broader repertoire of viruses over time as well as by the occurrence of novel viruses or virus genotypes in the heart. The association between severe acute respiratory syndrome coronavirus (SARS-CoV) and SARS-CoV-2 and inflammatory cardiomyopathy is not yet clear. '(?)' denotes unclear, needing further investigation; HIV, human immunodeficiency virus. Based on data from REF. ${ }^{308}$.

of the genetic background on disease progression and outcome. Furthermore, mutant strains of coxsackievirus B3 (CVB3) with 5'-terminal deletions in their genomic RNA have been isolated from a patient with idiopathic dilated cardiomyopathy (DCM), a mutation that has been suggested as a possible mechanism of viral persistence in the heart ${ }^{27}$. Indeed, a later study showed that persistent forms of group B enteroviruses harbour a 5 '-terminal deletion in their genomic RNAs and that these viruses can impair cardiomyocyte function through the proteolytic activity of viral proteinase $2 \mathrm{~A}$ in patients with unexplained $\mathrm{DCM}^{28}$. Beyond providing a potential mechanism for viral persistence, this study suggests that conventional PCR might not be capable of detecting these mutant viruses ${ }^{29}$.

Parvovirus B19. B19V infection is associated with a broad range of clinical manifestations. B19V infections are usually mild and self-limiting, but can also induce severe septic and haematological complications. B19V can cause acute cardiac infection during severe viraemia $^{30}$, but B19V infection can also persist in the heart with virus reactivation episodes ${ }^{6}$. This vasculotropic virus can enter endothelial cells and trigger the release of pro-inflammatory cytokines mediated by the toxic, non-structural viral protein NS1 (REF. $\left.{ }^{31}\right)$. B19V infection of endothelial cells can thereby induce cardiomyocyte apoptosis, as shown in vitro in B19V-infected endothelial cells co-cultured with cardiomyocytes ${ }^{32}$. Sustained severe cardiac inflammation, especially in the setting of acute B19V infection, might lead to cardiomyocyte necrosis ${ }^{33}$. How B19V persistence in the heart affects clinical outcomes is still under discussion ${ }^{34,35}$. The aetiological role of $\mathrm{B} 19 \mathrm{~V}$ infection in the development of myocarditis is also unclear, given that $\mathrm{B} 19 \mathrm{~V}$ is often found in myocardial autopsy samples from individuals without myocarditis or $\mathrm{DCM}^{36,37}$. This observation suggests that the presence of B19V DNA in cardiac tissue might indicate in most cases that $\mathrm{B} 19 \mathrm{~V}$ is a non-specific bystander of myocarditis rather than the main pathogen causing the disease ${ }^{38}$. Only the presence of high copy numbers of B19V DNA in cardiac tissue ( $>500$ viral DNA copies per microgram of cardiac DNA) is currently considered to be related to myocarditis ${ }^{39}$. Beyond a high B19V DNA copy number in the heart ${ }^{40,41}$, the presence of active replicating $\mathrm{B} 19 \mathrm{~V}$ with detectable viral $\mathrm{RNA}^{42}$, as well as the co-presence of lymphotropic viruses (such as HHV6) ${ }^{40}$, is thought to be related to myocarditis, but this finding needs to be further investigated ${ }^{32}$. The majority of EMB samples from patients with acute myocarditis or inflammatory cardiomyopathy have low copy numbers of B19V DNA, which raises the question about the aetiopathogenic role of persistent B19V infection as a relevant trigger of chronic inflammatory heart disease.

Herpesviridae. Viruses belonging to the Herpesviridae family (such as Epstein-Barr virus, HHV6 and cytomegalovirus) can have lifelong persistence in the body. Epstein-Barr virus was found to induce a severe, chronic active infection of $\mathrm{CD}^{+} T$ cells in the myocardium in a patient with ongoing perimyocarditis ${ }^{43}$. The most prevalent cardiac herpesvirus, HHV6, which also infects T cells, is divided into the subgroups HHV6A and HHV6B. Interestingly, the HHV6 genome can be integrated into the DNA of somatic cells or germ line cells $^{44}$. Whether the integrated HHV6 copies can be reactivated and induce myocarditis is still unclear.

$H I V$, hepatitis $C$ virus and influenza $A$ and $B$ viruses. Myocarditis associated with $\mathrm{HIV}^{45}, \mathrm{HCV}^{46}$ or influenza virus $^{47}$ infections has been suggested to result from immune-mediated effects. The persistence of $\mathrm{HCV}$ infection and development of DCM have been linked to the genetic background of the patients, with $H L A$ $D P B 1^{\star} 0901$ and $H L A-D R B 1^{*} 1201$ alleles being more prevalent in these patients ${ }^{46}$.

Coronaviridae. Coronaviruses, belonging to the Coronaviridae family, are classified into four groups, Alphacoronavirus, Betacoronavirus, Gammacoronavirus and Deltacoronavirus, of which Alphacoronavirus and Betacoronavirus are known to cause infection in 
humans ${ }^{48}$. Different members of Coronaviridae constantly circulate in the human population, usually causing mild respiratory disease ${ }^{49}$. By contrast, MERS-CoV, SARS-CoV and SARS-CoV-2 can be transmitted from animals to humans to cause severe respiratory diseases ${ }^{50}$. To date, older age ( $>60$ years), male sex and presence of comorbidities, including hypertension and obesity, are known to be the major risk factors for death in patients with COVID-19 (REFS ${ }^{51,52}$ ). Presence of cardiac injury (defined by elevated troponin levels in plasma), increased levels of D-dimer or IL-6 in plasma, and acute respiratory distress syndrome are other strong and independent factors associated with mortality in these patients ${ }^{20}$. The suggested mechanisms of myocardial injury in patients with COVID-19 include myocardial damage by a cytokine storm triggered by an imbalanced response of $\mathrm{T}$ helper 1 cells $\left(\mathrm{T}_{\mathrm{H}} 1\right.$ cells) and $\mathrm{T}$ helper 2 cells $\left(\mathrm{T}_{\mathrm{H}} 2\right.$ cells $)^{53,54}$, and respiratory dysfunction and hypoxaemia caused by SARS-CoV-2 infection ${ }^{55}$. Myocardial injury might also be attributable to decreased activity of the ACE2-angiotensin (1-7) axis, which has cardiovascular protective effects as a counter-regulatory element of angiotensin II signalling ${ }^{56}$. ACE2 and angiotensin (1-7) levels have been shown to be reduced in autopsy heart samples from patients with a positive test for SARS$\mathrm{CoV}^{57}$. In addition, ACE2 is the entry receptor for coronaviruses, including SARS-CoV ${ }^{58}$ and SARS-CoV-2 $\left(\right.$ REF $\left.^{59}\right)$, into host cells. SARS-CoV and SARS-CoV-2 entry into the host cell requires binding of the viral spike protein to ACE2 and spike protein priming mediated by the host cell serine proteases TMPRSS2, cathepsin B and cathepsin $\mathrm{L}^{59,60}$. TMPRSS2 is present on lung cells that express ACE2, and has been shown to be essential for viral entry ${ }^{59}$. Nicin and colleagues showed that cardiac cells including cardiomyocytes, pericytes, fibroblasts, endothelial cells and leukocytes from patients with HF with reduced ejection fraction or with aortic stenosis express ACE2 (REF ${ }^{61}$ ). Similar to these findings, our group analysed a single EMB sample from a patient with DCM and found that ACE2 is mainly expressed in cardiomyocytes, pericytes and fibroblasts, although these cardiac cells did not express TMPRSS2 (N.H, H.M., C.T., S.V.L., unpublished observations). SARS-CoV-2 has also been detected in macrophages in cardiac tissue, which suggests that SARS-CoV-2 can reach the heart during transient viraemia or through infiltration of infected macrophages into the myocardium ${ }^{62}$. Furthermore, presence of viral elements within endothelial cells and an accumulation of inflammatory cells in the myocardium, with evidence of endothelial and inflammatory cell death indicative of endotheliitis, has been reported ${ }^{63}$. So far, the classic type of acute lymphocytic myocarditis or lymphocytic inflammatory cardiomyopathy has not been detected in patients with COVID-19 (REF. ${ }^{12}$ ). Further insights into SARS-CoV-2 infection and myocardial damage are needed for the appropriate classification of the associated heart disease.

\section{Knowledge gaps and future directions.}

- Improve viral detection methods, given that current diagnostic methods have low sensitivity for viral genome detection in heart samples.
- Adopt next-generation sequencing (NGS) and metagenomics approaches that allow unbiased pathogen detection ${ }^{64}$ to improve the accuracy of diagnosis, given that knowledge about mutant viruses and 'new' viruses associated with inflammatory cardiomyopathy is lacking.

- Understand the diagnostic distinction between active versus persistent and/or latent viral cardiac infection.

- Understand the pathogenic and prognostic importance of viral load.

- Understand the role of the patient genetic background and sex on the progression and outcome of viral myocarditis.

- Develop registries to assess the presence and type of viruses in acute myocarditis versus chronic inflammatory cardiomyopathy and paediatric versus adult patient populations.

- Develop vaccines against viruses related to myocarditis.

- Understand the pathogenic mechanisms of SARS-CoV2-associated heart disease.

\section{Role of immune cells}

Our understanding of the role of immune cells in inflammatory cardiomyopathy is evolving. The importance of immune cells in the pathogenesis of viral myocarditis and viral inflammatory cardiomyopathy has been demonstrated in experimental mouse model ${ }^{65}$.The pathogenic process of viral inflammatory cardiomyopathy can conceptually be divided into three phases: an acute phase of viral entry into the cell and activation of the innate immune response (which can last 1-7 days), a subacute phase with activation of the adaptive immune response (which can last 1-4 weeks), and a chronic phase that can last from months to years, in which delayed or ineffective viral clearance together with chronic inflammation and cardiac remodelling can lead to $\mathrm{DCM}^{66}$.

Upon infection, the innate immune response is activated. Innate immune cells, as well as cardiac cells including cardiomyocytes, are activated via recognition by pattern recognition receptors, including Toll-like receptors (TLRs) ${ }^{67}$ and nucleotide-binding oligomerization domain-like receptors ${ }^{68,69}$, of specific molecular patterns of pathogens (termed pathogen-associated molecular patterns (PAMPs)) and patterns released from endogenous damaged cells (termed damage-associated molecular patterns (DAMPs)), such as released ATP, S100A8 and S100A9 (REF.70). The type of pattern recognition receptor and downstream signalling can differ depending on the pathogen or DAMP. The activated innate immune cells and cardiac cells release cytokines, chemokines, interferons and alarmins, leading to further activation and homing of innate immune cells to the heart, including mast cells, neutrophils, dendritic cells, monocytes and macrophages ${ }^{71}$. Monocytes and macrophages are the main inflammatory cell subsets found in human and experimental myocarditis ${ }^{71}$. Although activation of the innate immune response in the heart is beneficial to the host owing to its antiviral effects, excessive or persistent activation of the innate immune system can lead to an exaggerated and/or chronic inflammatory process that triggers myocardial 


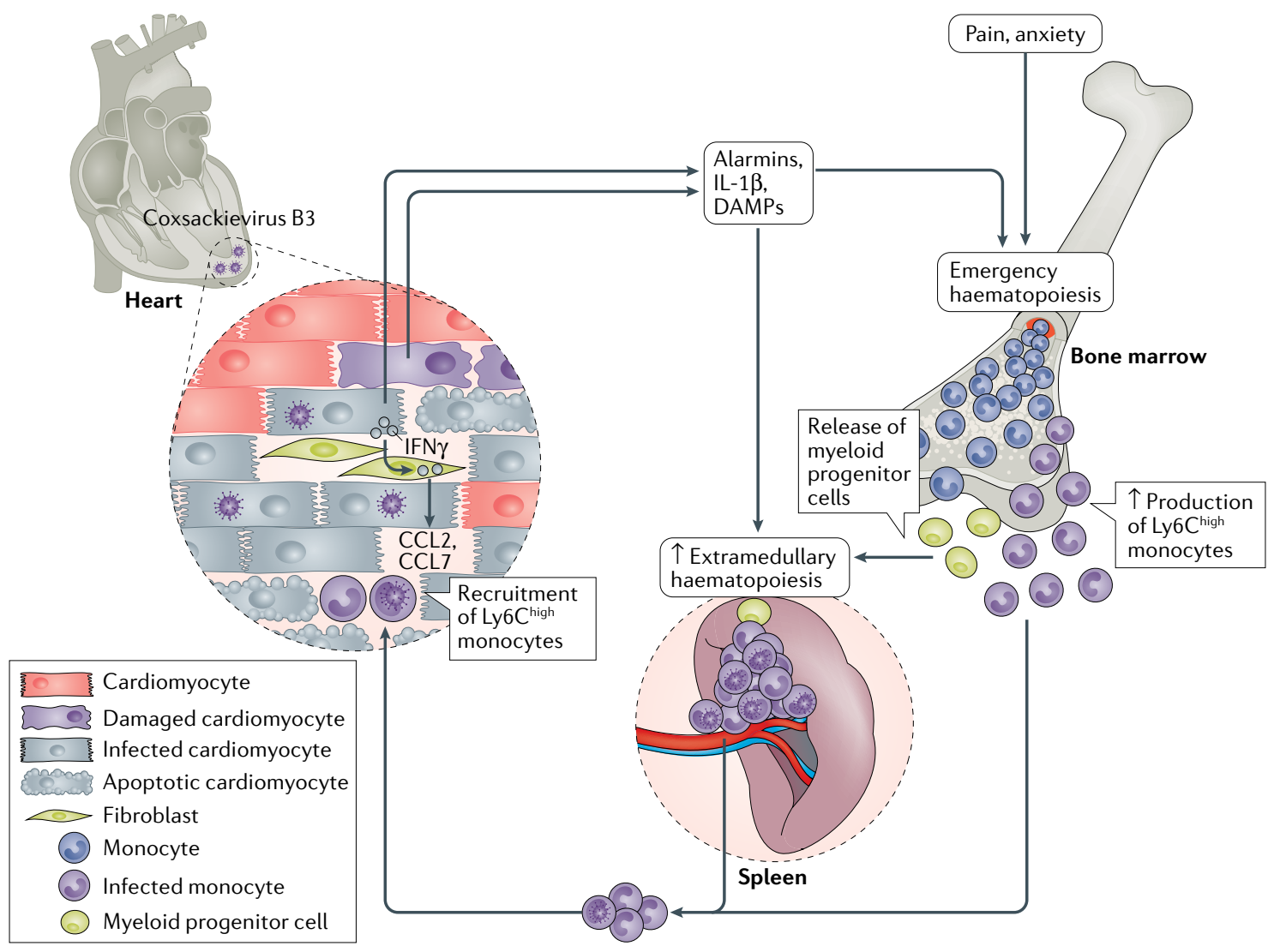

Fig. 2 | Cardiosplenic axis in coxsackievirus B3-induced myocarditis. In the heart, coxsackievirus B3 infection of cardiomyocytes leads to cell damage and death and the release of IL-1 $\beta$ and damage-associated molecular patterns (DAMPs), which trigger the recruitment and activation of cells from the innate immune system. Pain, anxiety and the release of danger signals into the systemic circulation trigger emergency haematopoiesis in the bone marrow, leading to medullary monocytopoiesis as well as release of myeloid progenitor cells into the circulation. Myeloid progenitor cells then migrate to the spleen, where extramedullary monocytopoiesis takes place to replenish the pool of proinflammatory Ly6Chigh monocytes, which can be rapidly mobilized to the damaged heart. In the heart, IFN $\gamma$ released by infected cardiomyocytes boosts the production by fibroblasts of the pro-inflammatory C-C motif chemokines CCL2 and CCL7, which promote the homing of Ly6Chigh monocytes to the heart. Given that the spleen is a target organ of coxsackievirus B3 and monocytes target cells of coxsackievirus B3, the recruited Ly6Chigh monocytes might be infected with coxsackievirus B3 and thereby transport the virus into the heart, further contributing to the viral infection. Activation of the innate immune system in the heart is beneficial for its antiviral effects but excessive or persistent activation can lead to exaggerated and/or chronic inflammation that triggers myocardial destruction and remodelling, culminating in cardiac dysfunction.

destruction and remodelling, culminating in cardiac dysfunction ${ }^{72}$.

The pain, anxiety and released danger signals (including alarmins and IL-1 $\beta$ ) triggered by the cardiac damage induce emergency haematopoiesis in the bone marrow, leading to medullary monocytopoiesis ${ }^{73}$ (FIG. 2). Monocytes and myeloid progenitor cells leave the bone marrow and myeloid progenitor cells migrate to the spleen, where extramedullary monocytopoiesis takes place $^{74}$. Consequently, the pool of pro-inflammatory monocytes in the spleen is replenished and can be mobilized to the damaged heart. The homing of immune cells, mainly monocytes, from the spleen into the heart (the so-called cardiosplenic axis) has been particularly assessed in the context of ischaemic heart disease ${ }^{75,76}$. Our understanding of the importance of the cardiosplenic axis in inflammatory cardiomyopathy and as a target to modulate the trafficking of immune cells to the heart ${ }^{77,78}$ in inflammatory cardiomyopathy stems from findings in mice with CVB3-induced myocarditis. In this mouse model, blunting the CCR2-CCL2 axis, which is involved in the recruitment of pro-inflammatory Ly6 $\mathrm{C}^{\text {high }}$ monocytes to the heart, attenuates myocarditis ${ }^{77-80}$. By contrast, blockade of the $\mathrm{CX}_{3} \mathrm{C}$ chemokine receptor 1 ( $\left.\mathrm{CX}_{3} \mathrm{CR} 1\right)-$ $\mathrm{CX}_{3} \mathrm{C}$ chemokine ligand $1\left(\mathrm{CX}_{3} \mathrm{CL} 1\right)$ axis, which is involved in the recruitment of anti-inflammatory monocytes, worsens CVB3-induced myocarditis ${ }^{81}$. Of note, the spleen is a target organ of CVB3, with mouse splenic $B$ cells, $C D 4^{+} T_{H}$ cells and macrophages and monocytes expressing $\alpha \mathrm{M} \beta 2$ integrin (also known as $\mathrm{Mac} 1$ ) as the target cells for CVB3 (REF. ${ }^{82}$ ). In humans, monocytes have also been identified as target cells of CVB3 $\left(\right.$ REF. $\left.^{83}\right)$. Therefore, homing of CVB3-infected immune cells into the heart can further contribute to cardiac viral infection and chronic inflammation ${ }^{78,80,84}$. Modulation of the cardiosplenic axis might help to block 
Regulatory T cells

( $\mathrm{T}_{\text {reg }}$ cells). A subpopulation of $\mathrm{CD}^{+} \mathrm{T}$ cells, constituting

$5-10 \%$ of the peripheral

$T$ cells, that have a pivotal

role in the induction and

maintenance of immune

homeostasis and tolerance.

$T_{\text {reg }}$ cells have multiple effector

functions and execute their

regulatory potency by directly suppressing T cells, B cells

and antigen-presenting cells, and also by interacting with non-immune tissue cells

Antigen-presenting cells (APCs). A heterogeneous group of immune cells that mediate the cellular immune response by processing and presenting antigens recognizable by T cells. Classic APCs include macrophages, dendritic cells $B$ cells and Langerhans cells.

\section{Neutrophil extracellular} traps

Complexes of chromosomal DNA, histones and granule proteins that are released by neutrophils and can entangle bacteria, thereby limiting infection.

Experimental autoimmune myocarditis

(EAM). EAM can be induced in susceptible mouse strains by immunization with selfpeptides derived from the myosin $\mathrm{H}$ chain together with a strong adjuvant, or by injection of activated, myosin $\mathrm{H}$ chain-loaded dendritic cells.

$\mathrm{T}_{\mathrm{H}} 17$ cells

A subset of $\mathrm{T}$ helper cells that fight microbial pathogens by secreting cytokines such as IL-17A, IL-17F and IL-22. this process; for example, with therapies that reduce monocytopoiesis, such as IL- $1 \beta$ inhibitors ${ }^{74}$, or with transfer of regulatory $T$ cells $\left(\mathrm{T}_{\text {reg }}\right.$ cells) ${ }^{80}$ and mesenchymal stromal cells $s^{69,78,85}$, which block the recruitment of pro-inflammatory monocytes into the heart.

Mast cells, natural killer cells and dendritic cells. Mast cells are among the first cells to respond to viral infection of the heart. Mast cells degranulate within $6 \mathrm{~h}$ of infection and produce pro-inflammatory cytokines such as tumour necrosis factor (TNF), IL- $1 \beta$ and IL- 4 . High numbers of mast cells are found in mice susceptible to autoimmune heart disease after CVB3 infection ${ }^{86}$. Viral infection also leads to the recruitment of natural killer cells $^{87,88}$ and dendritic cells ${ }^{89}$, which prevent the development of myocarditis. In mice with enterovirus-induced myocarditis, signalling mediated by the activating receptor NKG2D in natural killer cells was found to protect against progression to inflammatory cardiomyopathy, leading to effective clearance of CVB3 from the heart ${ }^{87}$. Dendritic cells have been reported to accumulate in the mouse heart after viral infection of the myocardium, coincident with monocyte infiltration and loss of resident reparative, embryonic cardiac macrophages ${ }^{89}$. After ingesting dead and damaged cardiomyocytes, dendritic cells migrate to regional lymph nodes and the spleen to present antigens to naive B cells and T cells, which initiates the activation of the adaptive immune response. The relevance of dendritic cells as antigen-presenting cells has been demonstrated in mouse studies showing that cardiac dendritic cell depletion abrogated the generation of antigen-specific $\mathrm{CD} 8^{+} \mathrm{T}$ cells, promoting the progression of subclinical cardiac injury into overt $\mathrm{HF}^{89}$. Dendritic cells can also process endogenous antigens and, therefore, might also trigger autoimmune myocarditis. Indeed, dendritic cells loaded with myosin peptides have been used to develop an experimental model of myosin-induced autoimmune myocarditis ${ }^{90}$.

Neutrophils. Neutrophils are among the first lines of defence against infection. In a mouse model of CVB3 myocarditis, an early (2.5 days) and abundant mobilization and influx of neutrophils into the heart and the pancreas occur after CVB3 infection ${ }^{91}$. This mobilization occurs earlier than that of any other infiltrated innate immune cells. Depletion of neutrophils in CVB3-infected mice results in reduced myocarditis ${ }^{92}$. Neutrophils can maintain inflammation by a specific process called NETosis, which involves the formation of neutrophil extracellular traps. The role of NETosis in promoting cardiac inflammation has been shown in mice with experimental autoimmune myocarditis (EAM) ${ }^{93}$, and the severity of acute myocardial inflammation in these mice is strongly associated with neutrophil accumulation in the heart ${ }^{94}$. The alarmins S100A8 and S100A9 released by neutrophils (and monocytes) are also involved in promoting inflammatory cardiomyopathy, as demonstrated by a study showing that $5100 a 9^{-/-}$ mice were protected from the detrimental effects of CVB3 infection ${ }^{95}$. Neutrophil numbers in blood positively correlate with the level of cardiomyocyte necrosis (measured by troponin I levels in plasma) in patients with acute coronary syndrome ${ }^{96}$. Likewise, plasma levels of the S100A8-S100A9 heterodimer are increased in patients with acute myocarditis when myocytolysis occurs, compared with the levels in healthy individuals ${ }^{70}$.

Monocytes. Monocytes are crucial effector cells in myocarditis ${ }^{97}$, comprising a major proportion of infiltrating cells in the heart. Monocytes are a heterogeneous, multifunctional cell population with a critical role in the pathogenesis of myocarditis. The role of the different monocyte subsets has been investigated in mouse models of myocarditis but so far has not been addressed in patients with myocarditis. In mice, the pro-inflammatory CD $115^{+} \mathrm{CD} 11 \mathrm{~b}^{+} \mathrm{Ly} 6 \mathrm{C}^{\text {high }} \mathrm{CCR} 2^{\text {high }} \mathrm{CX} 3 \mathrm{CR} 1^{\text {low }}$ and $\mathrm{CD} 115^{+} \mathrm{CD} 11 \mathrm{~b}^{+} \mathrm{Ly} 6 \mathrm{C}^{\text {middle }} \mathrm{CCR} 2^{\text {high }} \mathrm{CX} 3 \mathrm{CR} 1^{\text {low }}$ monocyte subsets (which are considered the counterparts of human classic $\mathrm{CD} 14^{++} \mathrm{CD} 16^{-} \mathrm{CCR} 2^{\text {high }} \mathrm{CX} 3 \mathrm{CR} 1^{\text {low }}$ and $\mathrm{CD} 14^{++} \mathrm{CD} 16^{+} \mathrm{CCR} 2{ }^{\text {middle }} \mathrm{CX} 3 \mathrm{CR} 1{ }^{\text {high }} \mathrm{CCR} 5^{+}$ monocytes ${ }^{98}$ ) infiltrate sites of cardiac inflammation and damage in response to chemokine signals ${ }^{99}$. The infiltrated monocytes differentiate into inflammatory macrophages that secrete pro-inflammatory cytokines, such as TNF and IL-6, and contribute to tissue degradation and $\mathrm{T}$ cell activation ${ }^{78,80}$. By contrast, CD $115^{+} \mathrm{CD} 11 \mathrm{~b}^{+} \mathrm{Ly} 6 \mathrm{C}^{\text {low }} \mathrm{CCR} 2^{\text {low }} \mathrm{CX} 3 \mathrm{CR} 1^{\text {high }}$ monocytes (corresponding to human non-classic $\mathrm{CD} 14{ }^{+} \mathrm{CD} 16^{++} \mathrm{CCR} 22^{\text {low }} \mathrm{CX} 3 \mathrm{CR} 11^{\text {high }}$ monocytes ${ }^{98}$ ) recruited to the inflamed cardiac tissue are more likely to differentiate into macrophages that secrete antiinflammatory cytokines and contribute to tissue repair $^{78,98}$. Cardiac fibroblasts secrete chemokines that promote the migration of monocyte subsets to the myocardium ${ }^{99}$ and also facilitate the differentiation of Ly6 $\mathrm{C}^{\text {high }}$ monocytes and Ly6 $\mathrm{C}^{\text {low }}$ monocytes into macrophages in mice with myocarditis ${ }^{100}$.

T cells and B cells. T cells, and to a certain extent B cells specific for viral antigens, are critical mediators of cardiac damage in experimental models of myocarditis ${ }^{65,80,101-103}$. Activation of the $\mathrm{T}$ cell system is believed to be the major pathophysiological mechanism underlying autoimmune myocarditis and autoimmune inflammatory cardiomyopathy ${ }^{104}$. The presence of activated T cells is essential for the cardiac damage in virus-induced myocarditis, as shown by studies indicating that impaired $\mathrm{T}$ cell maturation protects against CVB3-induced myocarditis in mice ${ }^{101}$. In another study in mice with CVB3-induced myocarditis, disease severity increased in mice lacking the CD8 receptor and was attenuated in mice lacking the $\mathrm{CD} 4$ receptor compared with wild-type mice, suggesting that different $\mathrm{T}$ cell subsets have different functions in virus-induced myocarditis ${ }^{105}$. Similar findings were observed in another study in which deficiency of $\mathrm{CD}^{+} \mathrm{T}$ cells in mice led to increased CVB3induced cardiac injury and chronic myocarditis, a process that was unrelated to perforin-mediated cytotoxicity ${ }^{106}$. Mice lacking T-box transcription factor TBX21 (T-bet) - which is essential for $\mathrm{T}_{\mathrm{H}} 1$ lineage differentiation and IFN $\gamma$ production - are highly susceptible to autoimmune myocarditis owing to the induction of IL-17 production ${ }^{107}$. In mice with EAM, $\mathrm{T}_{\mathrm{H}} 17$ cells promote the progression to $\mathrm{DCM}^{102}$. By contrast, $\mathrm{T}_{\text {reg }}$ cells, 
which are reduced in patients with myocarditis or $\mathrm{DCM}^{108}$, protect against the development of CVB3induced myocarditis in mice by attenuating cardiac inflammation ${ }^{80,103}$. IL-23, which is primarily secreted by antigen-presenting cells, induces an increase in the ratio of $\mathrm{T}_{\mathrm{H}} 17$ cells to $\mathrm{T}_{\text {reg }}$ cells by promoting the maturation of $\mathrm{T}_{\mathrm{H}} 17$ cells $^{109}$, and is an important trigger for the initiation of autoimmune myocarditis in mice ${ }^{110}$.

Limited data are available on the role of B cells in the progression of myocarditis to DCM. Detection of infected activated B cells both in the heart tissue of CVB3-infected immunocompetent mice and in severe combined immunodeficient mice receiving splenocytes from CVB3-infected syngeneic donors ${ }^{84}$ supports the concept that $B$ cell traffic might contribute to the maintenance of chronic inflammatory heart disease. B cells are a crucial link between the innate and adaptive immune system. In addition to antigen-specific B cell receptors, $\mathrm{B}$ cells also express TLRs. TLR signalling is associated with B cell activation and tolerance and with diverse pathological conditions, such as viral myocarditis and septic cardiomyopathy ${ }^{111}$. Most of the information on the role of B cells in inflammatory cardiomyopathy is derived from the identification of autoantibodies implicated in $\mathrm{DCM}^{111}$. Autoantibodies, such as those against $\beta_{1}$-adrenergic receptor, mitochondrial components, cardiac myosin heavy chain isoforms, cardiac troponin, $\mathrm{Na}^{+} / \mathrm{K}^{+}$-ATPase and other heart-related proteins, might contribute to cardiac dysfunction ${ }^{111}$. Additionally, findings from a study in patients with subacute or chronic inflammatory myocarditis suggest that $\mathrm{CD} 20^{+} \mathrm{B}$ cells which induce myocardial damage in mice by activating $\mathrm{T}$ cells $\mathrm{s}^{112}$ and triggering monocyte mobilization ${ }^{113}$ could have a pathophysiological role in inflammatory cardiomyopathy ${ }^{114}$.

Eosinophils. Patients with eosinophilia frequently develop cardiomyopathies ${ }^{115}$. Eosinophils are also implicated in parasite-mediated, drug-induced or hypersensitivity myocarditis with progression to DCM, as shown by studies in mice with EAM. Eosinophildeficient mice with EAM were protected from developing DCM, whereas hypereosinophilic mice with EAM had a more rapid progression to DCM, mediated by eosinophil-derived IL-4 (REF. ${ }^{115}$ ). The eosinophil cationic protein derived from degranulation of eosinophils has an important role in the pathogenesis of eosinophilic myocarditis in mice ${ }^{116}$. Major basic protein, the most abundant protein in eosinophilic granules, is highly thrombogenic and contributes to the high rate of vascular thromboembolism in patients with eosinophilic myocarditis ${ }^{117}$. Treatment with mepolizumab, an antibody against IL-5 (a key mediator of eosinophil maturation and survival), was found to be effective in a patient with eosinophilic myocarditis ${ }^{118}$.

\section{Knowledge gaps and future directions.}

- Improve our understanding of how the immune cell response switches from host defence to host injury.

- Generate data on ratios of $\mathrm{T}_{\text {reg }}$ cells to $\mathrm{T}_{\mathrm{H}} 17$ cells in patients with myocarditis or inflammatory cardiomyopathy.
- Understand why only some patients with viral myocarditis or inflammatory cardiomyopathy show autoimmunity or abnormal immune cell responses.

- Understand why some patients with autoimmunity or abnormal immune cell responses do not develop myocarditis or inflammatory cardiomyopathy.

- Improve our knowledge of the genetic and epigenetic factors involved in maladaptive immune cell responses.

- Understand how to target autoimmunity or neutralize immune cell functions involved in the pathophysiology of inflammatory cardiomyopathy without an associated risk to the host.

- Improve our knowledge of the role of neutrophils in viral myocarditis.

- Assess whether genetic cardiomyopathies have an immune cell component.

- Understand how research on cardiac immune cells from mouse models can be applied to humans.

\section{Role of autoimmunity}

The involvement of autoimmunity in inflammatory cardiomyopathy is well established. Inflammatory cardiomyopathy fulfils the Rose-Witebski diagnostic criteria for organ-specific autoimmune disease, including: presence of immune cell infiltrates and abnormal expression of HLA class II and/or adhesion molecules in the absence of viral genomes in EMB samples from both index patients and family members ${ }^{34,119}$; presence of circulating heart-specific autoantibodies in patients with inflammatory cardiomyopathy and their relatives ${ }^{2,120-122}$; availability of animal models of experimentally induced inflammatory cardiomyopathy, with or without a DCM phenotype, after immunization with specific autoantigen $(\mathrm{s})^{2,123-125}$; and response to immunosuppression or immunomodulation in patients with virus-negative inflammatory cardiomyopathy ${ }^{2,126-128}$.

Heart-specific autoantibodies. Heart-specific autoantibodies are present in up to $60 \%$ of patients with inflammatory cardiomyopathy and their relatives ${ }^{2,129,130}$. These autoantibodies recognize many cardiac autoantigens, particularly cardiac $\alpha$-myosin heavy chain (also known as myosin 6) and $\beta$-myosin heavy chain (also known as myosin 7) isoforms ${ }^{131}$. Some of these autoantibodies seem to have a direct pathogenic and/or prognostic role ${ }^{132,133}$. Immunization of animals with autoantigens that have been identified in patients with inflammatory cardiomyopathy, such as $\beta_{1}$-adrenergic receptor, muscarinic acetylcholine receptor $\mathrm{M}_{2}$, cardiac myosin heavy chain isoforms and cardiac troponin ${ }^{123-125,134-136}$, leads to cardiac abnormalities that mimic the human disease phenotype. Passive transfer of antibodies purified from rats immunized with cardiac myosin leads to antibody deposition in the myocardium and myocyte apoptosis, producing cardiomyopathy in recipient animals ${ }^{125}$. Both antibodymediated and cell-mediated autoimmune forms of inflammatory cardiomyopathy have been shown in animal models, but whether both forms can be found in patients is still unknown because most studies in patients with inflammatory cardiomyopathy to date have investigated humoral rather than cellular immune mechanisms. 
Gene-environment interactions. Autoimmune inflammatory cardiomyopathy can occur in the context of systemic immune-mediated diseases ${ }^{9}$ or be iatrogenic (for example, induced by immune checkpoint inhibitor therapy ${ }^{8}$ ). Inflammatory cardiomyopathy might also have a hereditary component, as shown in a genomewide association study in patients with $\mathrm{DCM}^{137}$. This study revealed a risk locus for idiopathic DCM encoding HLA class I and HLA class II proteins, suggesting a role for genetically driven, autoimmune inflammatory processes in the pathogenesis of idiopathic $\mathrm{DCM}^{137}$. After the MOGE(S) classification ${ }^{138,139}$, autoimmune inflammatory cardiomyopathy probably represents a common end-stage resulting from a combination of several aetiological factors in a multifactorial cascade involving gene-environment interactions ${ }^{140}$. For example, patients with myocarditis have detectable immune reactivity to both myosin 6 antigens and myosin peptide mimics derived from commensal Bacteroides species from the gut ${ }^{141}$. These findings fit with the gene-environment interaction model and suggest that targeting the microbiome of genetically predisposed patients with myocarditis might reduce disease severity and, therefore, might help prevent the potentially lethal consequences of inflammatory cardiomyopathy ${ }^{141}$.

\section{Knowledge gaps and future directions.}

- Understand how the genetic background influences the susceptibility to immune-mediated disease in patients with inflammatory cardiomyopathy, including the role of HLA genotyping for disease management.

- Improve our understanding of autoimmunity triggers (for example, viruses, drugs and other environmental agents).

- Improve the definition of potential humoral predictors (such as distinct autoantibody specificities, pathogenic immunoglobulin class and IgG subclass, autoantibody titre and new relevant autoantigens) and cellular predictors (immune phenotype of circulating $\mathrm{T}$ cells, in particular $\mathrm{T}_{\mathrm{H}} 1, \mathrm{~T}_{\mathrm{H}} 17$ and $\mathrm{T}_{\mathrm{reg}}$ cells, and of myocardium-infiltrating cells, such as T cells, $B$ cells and myeloid cells) of the risk of progression to HF, death or heart transplantation, and of spontaneous or immunosuppressive therapy-induced recovery in patients with inflammatory cardiomyopathy.

- Assess the potential role of peripheral and myocardial levels of inflammatory and pro-fibrotic cytokines (for example, IL-1, IL-6, IL-17, IL-23 and TGF $\beta$ ) in patient risk stratification.

- Understand how to distinguish a beneficial immune reaction to clear a pathogen from a pathogenic autoimmune reaction.

- Assess the effect of gut microbiome modulation on the course of inflammatory cardiomyopathy.

\section{Translational research models}

Several animal models of myocarditis have been developed and tested that cover different underlying aetiologies, including virus-induced myocarditis, Trypanosoma cruzi-induced myocarditis and autoimmune myocarditis ${ }^{93-95}$. The approaches include the use of pathogens as well as engineered models such as transgenic mice (for example, Il5-transgenic mice, which develop eosinophilic myocarditis) $)^{115}$. The advantage of infectious models is that they more closely reflect the physiological processes of the human disease than models of autoimmune myocarditis, given that infectious models couple the immune response involved in pathogen clearance with autoimmune responses. Conversely, autoimmune myocarditis models facilitate the investigation of the progression of myocarditis to inflammatory cardiomyopathy and DCM and the involvement of specific components of the immune system in the disease process $^{142}$ (for example, use of $P d 1^{-/-}$mice to assess the role of the immune checkpoint PD1 (REF. $\left.{ }^{136}\right)$ ).

The mouse model of CVB3-induced myocarditis was established 60 years ago $^{143}$ and has become the standard for the evaluation of virus-induced myocarditis given its similarity to the myocardial injury observed in humans ${ }^{144}$. However, these mice have severe pancreatitis and a high systemic inflammatory response and, therefore, mainly mimic CVB3 infection in infants rather than in adult patients ${ }^{145}$. A study in a mouse model of CVB3 infection targeted to the heart and with attenuated virulence in the pancreas indicates that the systemic inflammatory response, rather than the cardiac damage induced by the infection, underlies the cardiac dysfunction observed in the classical CVB3 myocarditis model. Further refinement of this new model is still needed to allow representation of CVB3-induced myocarditis in adult patients. In addition, to improve the clinical relevance of animal models of viral myocarditis, models of B19V-induced myocarditis need to be developed given that $\mathrm{B} 19 \mathrm{~V}$ is currently the most frequently detected virus in EMB samples from patients with myocarditis ${ }^{10}$. Data indicate that this vasculotropic virus ${ }^{33,39}$ induces endothelial damage $\mathrm{e}^{32,146}$ and that patients with $\mathrm{B} 19 \mathrm{~V}$ infection have diastolic dysfunction ${ }^{147}$ and elevated levels of circulating endothelium-derived microparticles ${ }^{148}$. However, whether persistent $\mathrm{B} 19 \mathrm{~V}$ infection is a bystander or has a causal role in inflammatory cardiomyopathy is unclear ${ }^{32}$. Humanized mouse models of B19V infection will shed light on the aetiological role of $\mathrm{B} 19 \mathrm{~V}$ infection in the development of inflammatory cardiomyopathy.

The influence of the mouse strain ${ }^{149}$ and $\operatorname{sex}^{21}$ on the immune status and, consequently, on the model of myocarditis is well established. However, the role of housing conditions on the outcome of myocarditis in mice remains under-studied. Mice are kept in 'pathogen-free' conditions in animal facilities and, consequently, have a predominantly naive immune system, which contrasts with the experienced immune system of patients. Other housing factors can also affect the clinical relevance of the myocarditis model; for example, mice exposed to bisphenol A leached from plastic cages and water bottles had increased myocarditis and pericarditis compared with mice housed in glass cages that drunk out of glass water bottles ${ }^{150}$. This finding clearly highlights that to improve the translation of experimental results to the clinical setting, advanced animal models are needed that better represent the human conditions, and which take into account not only the immune experience of the animal model, but also the environmental factors common to a Western lifestyle, such as exposure to plastics, 
intake of processed foods, antibiotic usage, physical inactivity and HF medications ${ }^{150-152}$. The complexity of the immune system and its involvement in inflammatory cardiomyopathy further underscore that experiments in animal models are essential to understand the fundamental mechanisms underlying the pathogenesis of this disease. In vitro models, including inducible pluripotent stem cell (iPSC)-derived cardiomyocytes, have been developed as antiviral drug screening platforms ${ }^{153}$. These cells could be used to test the efficacy of antiviral agents in counteracting the direct cytotoxic effects of the virus. However, the use of iPSC-derived cardiomyocytes in vitro does not mimic the in vivo conditions for toxicity testing and does not take into account the systemic immune effects associated with inflammatory cardiomyopathy ${ }^{154}$.

\section{Knowledge gaps and future directions}

- Develop advanced animal models that more closely represent the human disease process, such as immune experience and exposure to environmental factors.

- Develop in vitro models that allow the study of immune cell interactions.

\section{Diagnosis and prognosis Clinical scenarios}

The typical symptoms and signs at presentation in patients with acute myocarditis include chest pain, dyspnoea, fatigue, palpitations, syncope and cardiogenic shock $^{4}$. Acute myocarditis can also present as sudden cardiac death, accounting for approximately $10 \%$ of deaths from sudden cardiac death in young individuals (aged $<35$ years) ${ }^{155}$. Prodromal manifestations, including fever, gastrointestinal disorders and influenza-like symptoms, are recorded in up to $80 \%$ of patients with acute myocarditis in the weeks preceding the acute phase ${ }^{3}$. A multicentre study showed that the type of presentation - specifically, complicated myocarditis (LV ejection fraction (LVEF) $<50 \%$ on first echocardiography, sustained ventricular tachycardia or haemodynamic instability at presentation) versus uncomplicated myocarditis - is associated with outcomes in patients hospitalized with suspected acute myocarditis (cardiac death or heart transplantation at 5 years was $14.7 \%$ versus $0 \%)^{3}$. In patients with preserved LVEF, assessment of late gadolinium enhancement (LGE) distribution patterns on cardiac MRI can improve patient risk stratification ${ }^{156,157}$. Among patients with fulminant myocarditis (patients who present with cardiogenic shock needing inotropes and/or mechanical circulatory support (MCS)), the histological subtype subtending the myocarditis, including giant-cell and eosinophilic myocarditis, is independently associated with increased mortality ${ }^{158}$.

Finally, inflammatory cardiomyopathy can be the first presentation in patients with HF symptoms and can be the result of a delayed diagnosis of acute myocarditis. Therefore, defining the time of cardiac symptom onset is crucial. A mild elevation of troponin levels in plasma that is disproportionate to the severity of the LVEF impairment and associated with a dilated left ventricle at presentation is suggestive of inflammatory cardiomyopathy rather than acute myocarditis ${ }^{158}$.
Patients presenting with inflammatory cardiomyopathy are often haemodynamically stable owing to a gradual and unrecognized attenuation of LV systolic dysfunction and remodelling. However, the recovery rate of patients with complicated myocarditis is only $50 \%{ }^{159}$. Currently, no established clinical markers are available to characterize the prognosis of patients with inflammatory cardiomyopathy.

\section{Knowledge gaps and future directions.}

- Determine the factors involved in the transition from acute myocarditis to chronic inflammatory cardiomyopathy in patients (an issue that has been addressed by few clinical studies ${ }^{160}$ ). Establish whether chronic inflammation, specific infection or both in the myocardium is critical in this transition or whether other mechanisms have a role, and determine the real incidence of the transition from acute myocarditis to chronic inflammatory cardiomyopathy among adults.

- Develop clinical research tools, including prospective registries of diverse patient populations, aimed at identifying patients at low risk versus those at high risk of developing chronic inflammatory cardiomyopathy. The accuracy of the risk stratification should be confirmed on the basis of uncomplicated versus complicated clinical presentation at the time of hospitalization $^{3}$ or on the basis of immunohistological ${ }^{34}$ or viral analysis data ${ }^{5,130}$ from EMB samples.

- Improve EMB-based diagnosis and identify innovative, non-invasive approaches for the diagnosis of myocarditis.

- Develop a multimarker approach including cardiac MRI to enable prognosis independently of the use of the LVEF.

- Identify specific biomarkers to guide diagnosis and treatment decisions.

\section{Imaging}

Currently, the non-invasive gold-standard method for the diagnosis of myocarditis is cardiac MRI (class I recommendation, level of evidence C in the 2012 ESC guidelines $^{161}$ ). In 2018, consensus guidelines recommended the addition of T2-weighted cardiac MRI to the pre-existing Lake Louise criteria (LLC) for the diagnosis of myocarditis ${ }^{162}$. The 2018 LLC showed better diagnostic performance than the original criteria owing to increased sensitivity ${ }^{163}$. T1 and T2 mapping have added further diagnostic information and accuracy to cardiac $\mathrm{MRI}^{164-169}$. In addition, parametric cardiac MRI modalities, such as T1 and T2 mapping, can facilitate the objective assessment of myocardial inflammation or diffuse myocardial fibrosis. However, the diagnostic accuracy of cardiac MRI might vary according to the clinical presentation and extent of cell necrosis in patients with EMB-proven acute myocarditis ${ }^{170}$. Cardiac MRI diagnostic sensitivity is high for infarct-like presentations, low for cardiomyopathy-like presentations and very low for arrhythmia presentations ${ }^{170}$. Furthermore, the type of myocarditis (that is, the specific immune cell infiltration and the underlying aetiology) cannot be established with the use of cardiac MRI. In routine clinical practice, 
many patients have borderline 'normal' T1 and T2 mapping values, which potentially leads to false-negative exclusion of myocarditis as a diagnosis. Data about the diagnostic and prognostic value of 'borderline' results are not available.

Cardiac MRI also allows the objective evaluation of myocardial deformation (strain), either with the use of new post-processing software tools on existing cine images or by acquisition of specific sequences (such as displacement encoding with stimulated echoes (DENSE) MRI or fast strain-encoded MRI). Strain can be evaluated in different layers of the myocardium and also in the right ventricle and left atrium ${ }^{171}$. Even years after acute myocardial inflammation, patients might present clinically with dyspnoea; by using strain analysis, diastolic impairment can be detected either by echocardiography or with a more complete assessment of the heart by cardiac MRI ${ }^{156,157,172}$. However, data on the combination of different cardiac MRI parameters and their added diagnostic and long-term prognostic value in patients with myocardial inflammation are still rare. In addition, current recommendations are based on classic assessment of cardiac MRI parameters and do not take into account advanced cardiac MRI parameters such as parametric mapping and strain. Moreover, cardiac MRI protocols for acute or chronic myocarditis specific for the different magnetic field strengths (1.5 T and 3.0 T) and for MRI scanners from different vendors need to be validated, and proof of the prognostic value of these protocols in large, multicentre trials is necessary to provide the basis for guideline recommendations. Cardiac MRI is also a potent tool for therapy monitoring in selected patients ${ }^{173}$ (TABLE 2). However, data on the best timing to perform follow-up cardiac MRI for therapy control in patients with myocardial inflammation are lacking.

Although the value of cardiac MRI in acute myocarditis has been widely proven, the technology continues to be under-used, partly owing to the limited availability of cardiac MRI in standard clinical practice ${ }^{174-176}$ (TABLE 2). Potential solutions to overcome this limitation might be the use of mobile cardiac MRI units associated with expert centres for interpretation, diagnosis and therapy recommendation. Additional essential factors to increase the use of cardiac MRI are appropriate training and increased awareness of the utility of cardiac MRI for the diagnosis of myocardial inflammation. Another factor limiting the widespread use of cardiac MRI in clinical practice are the difficulties for the reimbursement of cardiac MRI associated costs in many regions worldwide, even though cost-effectiveness and value for the health-care system have been proven for various clinical indications ${ }^{177-179}$. In addition, the utility of cardiac MRI is often limited in patients with haemodynamic instability owing to fast or irregular heart rates and mechanical ventilation ${ }^{2,162}$. In these patients and in patients with myocarditis presenting as acute HF with high-grade heart block, symptomatic ventricular tachycardia or shock, an EMB-guided approach is recommended (AHA and ESC class I recommendation, level of evidence B) $)^{2,13,180}$ (TABLE 2). New real-time cardiac MRI protocols for the assessment of anatomy, function and flow in these patients are under development ${ }^{181,182}$. Likewise, an EMB-based diagnostic approach is needed in patients in whom the onset of the disease occurred $>3$ months previously and the diagnostic accuracy of cardiac MRI is low ${ }^{162,168,183}$, such as in patients with HF of $>3$ months duration that is associated with a dilated left ventricle.

Patterns of LGE, the potential progression of LGE and the extent of focal fibrosis on cardiac MRI have been shown to predict the risk of hospitalization and adverse cardiovascular events in patients with suspected myocarditis ${ }^{184-186}$. Even in patients with myocarditis who seem to show clinical improvements, LGE can increase on imaging and should be considered as an indicator of

Table 2 | Cardiac MRI versus endomyocardial biopsy in routine clinical practice

\begin{tabular}{|c|c|c|c|}
\hline Clinical scenario & Characteristics & $\begin{array}{l}\text { Cardiac } \\
\text { MRI }\end{array}$ & $\begin{array}{l}\text { Endomyocardial } \\
\text { biopsy }\end{array}$ \\
\hline \multirow{3}{*}{$\begin{array}{l}\text { Suspected acute myocarditis } \\
\text { (disease onset } \leq 30 \text { days) }\end{array}$} & Cardiogenic shock & - & \multirow[t]{2}{*}{$++^{\mathrm{a}, \mathrm{b}}$} \\
\hline & Complicated, impaired ejection fraction or arrhythmias & ++ & \\
\hline & $\begin{array}{l}\text { Uncomplicated, stable, preserved ejection fraction and } \\
\text { no arrhythmias }\end{array}$ & + & $-/(+)^{\mathrm{a}, \mathrm{c}}$ \\
\hline \multirow{3}{*}{$\begin{array}{l}\text { Suspected inflammatory } \\
\text { cardiomyopathy } \\
\text { (disease onset }>30 \text { days) }\end{array}$} & Persistent heart failure symptoms in preserved EF & $++^{c}$ & $+^{\mathrm{a}, \mathrm{b}}$ \\
\hline & $\begin{array}{l}\text { Persistent heart failure symptoms and reduced EF } \\
\text { despite optimal medical therapy }\end{array}$ & $++^{c}$ & $++^{\mathrm{a}, \mathrm{b}}$ \\
\hline & Significant arrhythmias despite optimal medical therapy & $++^{c}$ & $++^{\mathrm{a}, \mathrm{b}}$ \\
\hline $\begin{array}{l}\text { Suspected acquired dilated } \\
\text { cardiomyopathy with a } \\
\text { disease onset of months }\end{array}$ & Impaired EF and dilated LV of unknown etiology & ++ & $+/++^{\mathrm{a}, \mathrm{b}}$ \\
\hline Ongoing clinical management & NA & + & $-1+^{d}$ \\
\hline \multicolumn{4}{|c|}{$\begin{array}{l}\text {-, not recommended; +, recommended; ++, highly recommended; NA, not applicable. }{ }^{\mathrm{a}} \text { For differential diagnosis; specific therapy } \\
\text { decision and selection. }{ }^{\circ} \text { Cardiac MRI or electroanatomical mapping-guided endomyocardial biopsy in selected patients. }{ }^{\mathrm{c} A} \text { negative } \\
\text { result does not exclude the persistence of low-grade cardiac inflammation in patients with severe cardiac complaints, refractory } \\
\text { to therapy. }{ }^{\mathrm{d} O p t i o n} \text { in selected patients who do not respond to therapy, to re-evaluate the diagnosis or to exclude viral reactivation. } \\
\text { Based on data from REFS }{ }^{71,159,162,307} \text {. }\end{array}$} \\
\hline
\end{tabular}


a Acute lymphocytic myocarditis
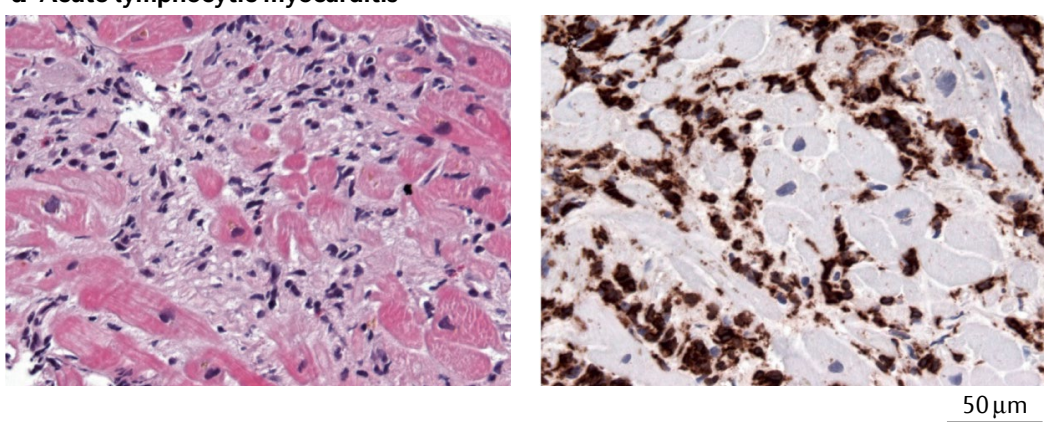

b Healing lymphocytic myocarditis
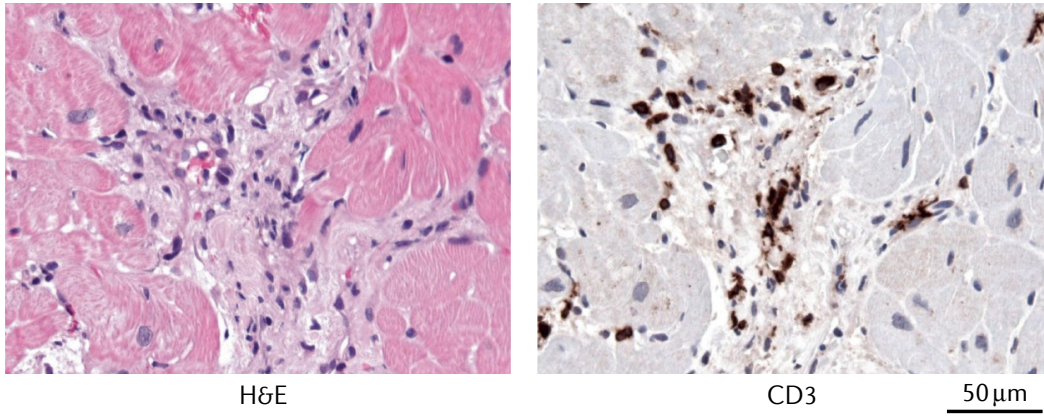

Fig. 3 | Diagnosis of lymphocytic myocarditis. Acute and healing lymphocytic myocarditis is diagnosed with histology and immunohistology of endomyocardial biopsy samples. a | Acute lymphocytic myocarditis caused by enterovirus A71 infection. Histology image showing cardiomyocyte necrosis (as revealed by the haematoxylin and eosin (HEE) staining in the left panel)) and immunohistology image showing diffuse infiltration of $\mathrm{CD}^{+} \mathrm{T}$ cells (as shown by anti-CD3 antibody staining (brown) in the right panel). $\mathbf{b} \mid$ Healing lymphocytic immune-mediated myocarditis. Histology image showing fibrosis but no cardiomyocyte necrosis (left panel) and immunohistology image showing the presence of infiltrated $C D 3^{+} T$ cells (right panel). All images $\times 400$.

Dallas criteria

The Dallas criteria were proposed in 1986 and provide a histopathological categorization for the diagnosis of myocarditis. According to the Dallas criteria, myocarditis requires an inflammatory infiltrate and associated myocyte necrosis or damage not characteristic of an ischaemic event, whereas in borderline myocarditis, a less intense inflammatory infiltrate and no light-microscopic evidence of myocytolysis (myocyte destruction) is evident the risk of adverse cardiovascular events ${ }^{187}$. Use of LGE parameters could also be an option for risk stratification in patients with cardiac sarcoidosis, independently of $\mathrm{LVEF}^{188} \cdot{ }^{18} \mathrm{~F}$-Fluorodeoxyglucose $\left({ }^{18} \mathrm{~F}-\mathrm{FDG}\right)$ uptake is a quantifiable surrogate parameter of increased glucose metabolism, which is a hallmark of inflammation. Therefore, ${ }^{18} \mathrm{~F}$-FDG PET is a valuable tool for diagnosis and monitoring treatment response in patients with cardiac sarcoidosis. In selected patients with myocarditis, the use of ${ }^{18} \mathrm{~F}$-FDG PET in addition to cardiac MRI might provide complementary information on disease progression $^{189}$.

New technologies to assess intraventricular pressure gradients or LV kinetic energy by $4 \mathrm{D}$ flow cardiac MRI are under development. Evaluation of LV kinetic energy or haemodynamic forces will potentially allow better characterization of patient populations at various stages of $\mathrm{HF}^{190}$ by providing quantitative measures, and might be of interest for diagnosis and therapy control in patients with myocardial inflammation.

The clinical value of vasodilator stress cardiac MRI for the quantitative assessment of microvascular disease has been proven. However, data about the use of this modality in patients with acute cardiac inflammation are sparse. Together with the quantitative assessment of myocardial strain, diffuse myocardial fibrosis and oedema by parametric mapping, cardiac MRI data might facilitate the generation of a potential objective cardiac MRI-based inflammation score.

\section{Knowledge gaps and future directions.}

- Current imaging methods have low predictive value in patients with chronic inflammatory cardiomyopathy and ongoing low-grade inflammation.

- Current imaging methods cannot detect the underlying aetiology of myocardial inflammation (for example, viral persistence), with the exception of PET for cardiac sarcoidosis.

- Develop standardized protocols specific for myocarditis across different cardiac MRI field strengths and scanners from different vendors.

- Generate data on advanced cardiac MRI parameters and their predictive value (including myocardial strain, parametric $\mathrm{T} 1$ and $\mathrm{T} 2$ mapping, $4 \mathrm{D}$ flow and LV kinetic energy, and haemodynamic forces) in patients with myocarditis.

- Assess for microvascular disease with the use of stress cardiac MRI in patients with suspected acute myocardial inflammation.

- Perform studies to assess the value of combining different imaging modalities for diagnosis and therapy control in patients with acute or chronic myocarditis.

- Evaluate cost-benefit, cost-effectiveness and budgetimpact models that include appropriate imaging methods for the management of acute or chronic myocardial inflammation.

- Develop a cardiac MRI inflammation score that is based on conventional and advanced cardiac MRI parameters.

\section{Endomyocardial biopsy}

EMB is the gold-standard method for the diagnosis of acute or chronic inflammatory heart diseases. Right ventricular (RV) and LV EMB are well accepted as standard procedures in the diagnostic work-up of patients with myocarditis, because biopsies are often the only method that allows the identification of the underlying aetiology of cardiac inflammation ${ }^{2,159,191-193}$. A 2013 ESC position paper advocates the characterization of cardiac inflammation using immunohistochemistry and viral genome analysis with quantitative PCR (real-time PCR and nested PCR with reverse transcription) for the diagnosis of myocarditis and the selection of therapeutic regimens ${ }^{2,159}$. Immunohistochemistry with the use of a panel of monoclonal and polyclonal antibodies (including anti-CD3, anti-CD68 and anti-HLA-DR antibodies) is recommended for the characterization of the inflammatory infiltrate ${ }^{194}$. Compared with the histological Dallas criteria, immunohistochemistry is more sensitive ${ }^{195}$ and has prognostic value ${ }^{34,191}$. Given that cardiac inflammation often has a patchy distribution, analysis of at least five or six tissue samples is suggested to reduce the EMB sampling error ${ }^{196}$ (FIG. 3). Furthermore, given the focal nature of many viral infections, two or three EMB samples are also recommended for the detection of viral nucleic acids to avoid false-negative results ${ }^{197,198}$ (FIG. 4). Despite this knowledge and the risk of under-diagnosing patients, the acceptance by clinicians of the need to take more than four EMB samples 
during a routine clinical procedure is often low, owing to the fear of complications such as ventricle perforation. Therefore, combined strategies involving EMB and imaging or electroanatomical mapping could be helpful in overcoming this problem. T2-mapping cardiac MRI might facilitate the identification of patients who would potentially benefit from undergoing EMB for therapeutic decision-making ${ }^{199,200}$ (TABLE 2). Moreover, use of 3D electroanatomical voltage mapping ${ }^{201-204}$, cardiac MRI $^{200}$ or ${ }^{18} \mathrm{~F}-\mathrm{FDG} \mathrm{PET}^{205}$ to guide EMB has been found to be helpful for increasing the sensitivity and specificity of the conventional EMB approach, by reducing sampling errors and allowing a deeper insight into different (local) pathologies $^{206}$ (FIG. 5).

At present, comprehensive datasets of the inflamed heart can be derived only from sophisticated molecular analyses of heart tissue samples, mainly obtained by EMB. Beyond the classic (immuno)histological and virological analyses, gene expression profiling has been suggested to contribute to the differential diagnosis of idiopathic giant-cell myocarditis and cardiac sarcoidosi $\mathrm{s}^{207}$. Targeted biopsies of the inflamed heart are required to study the role of omics technologies, such as genomics, epigenomics, proteomics and metabolomics, in diagnosis and drug discovery, which have to be correlated with state-of-the-art methods including histology, immunohistochemistry and molecular virology. A study using global proteome profiling has shown that inflammatory heart disease is associated with extracellular matrix remodelling and a decrease in the levels of
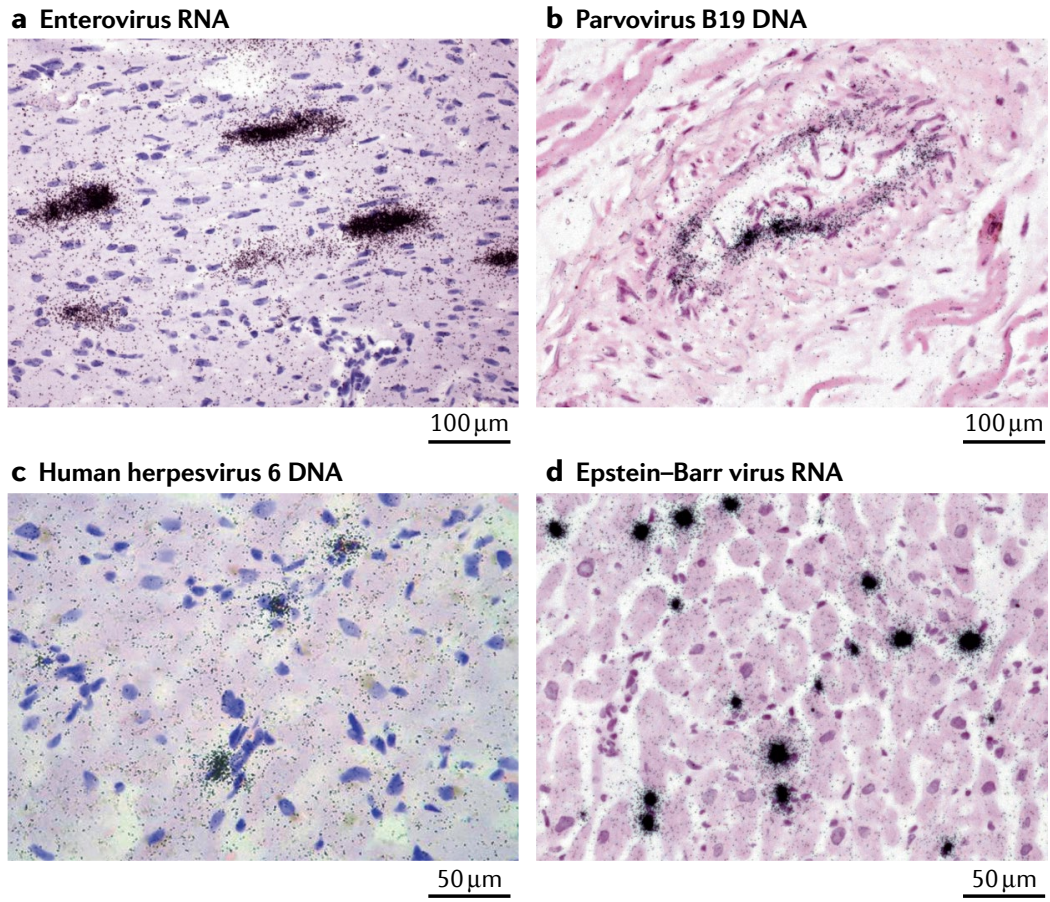

Fig. 4 | Visualization of viral nucleic acids in acute myocarditis. Viral nucleic acids in heart tissue samples from patients with acute myocarditis can be detected with radioactive in situ hybridization (black spots). Cell nuclei (purple) and cell cytoplasm and extracellular matrix (pink) are visualized with haematoxylin and eosin staining. Enteroviruses (panel a) infect and lyse cardiomyocytes, parvovirus B19 (panel b) infects endothelial cells, and human herpesviruses (panel c) and Epstein-Barr viruses (panel d) replicate in immune cells. Panels $\mathbf{a}$ and $\mathbf{b} \times 400$, panels $\mathbf{c}$ and $\mathbf{d} \times 630$. proteins involved in carbohydrate metabolism, the tricarboxylic acid cycle and oxidative phosphorylation ${ }^{208}$. Mass spectrometry analysis of EMB samples, which allows region-specific evaluation of protein profiles, allowed patient clustering to discriminate patients with from those without cardiac inflammation ${ }^{209}$. The characterization of patient epigenetic profiles combined with other genetic approaches including NGS can shed light on complex gene networks in patients with myocarditis who develop $\mathrm{HF}^{210}$. Use of NGS has led to the identification of an increasing number of gene variants and mutations associated with the risk of heart diseases such as DCM. With the expanded use of genome sequencing, the identification of further high-risk gene variants seems likely, which will thereby improve the clinical decision-making process and provide insights into the pathogenetic mechanisms of inflammatory cardiomyopathy. Successful integration of these omics techniques into existing diagnostic algorithms will contribute to a more sensitive, specific and cost-effective approach for the personalized treatment of patients with inflammatory cardiomyopathy ${ }^{211}$. Use of NGS will also facilitate the detection of so-far-unknown pathogenic, cardiotropic agents, such as DNA and RNA viruses, in myocarditis ${ }^{212}$.

Heart tissue samples have a considerable cell heterogeneity, which makes establishing the contribution of specific cell types to the pathogenesis of myocarditis difficult. New methods such as single-cell RNA sequencing of cardiomyocytes offer great opportunities for studying cardiac pathology at single-cell resolution ${ }^{213}$. Single-cell RNA sequencing also opens up the field of cardio-immunology, as shown by a study that mapped the immune cell activation profile in the heart in a mouse model of $\mathrm{HF}^{214}$.

The profound characterization of EMB samples via phenomics (such as proteomics, viral diagnosis and immune cell profiling) together with the clinical characterization of the patient (known as phenomapping ${ }^{209,215}$, that includes, for example, electrocardiography, echocardiography and laboratory and physical tests) will allow improved diagnosis and differentiation of the type of inflammatory cardiomyopathy, with the ultimate goal of defining therapeutically homogeneous patient subpopulations to improve patient outcomes ${ }^{209}$ (FIG. 6).

\section{Knowledge gaps and future directions.}

- Standardize the diverse immunohistochemistry markers and protocols for analysing EMB samples; for example, use of formalin-fixed tissue versus frozen tissue sections or the most appropriate antibodies to use $\mathrm{e}^{195}$.

- Define thresholds for the number of different cell types required for diagnosis and prognosis of myocarditis and inflammatory cardiomyopathy.

- Standardize the number of biopsies required for histology, immunohistology and viral diagnostics.

- Develop a more detailed classification of the specific immune cell subtypes (such as $\mathrm{T}_{\text {reg }}$ cells, $\mathrm{T}_{\mathrm{H}} 17$ cells and pro-inflammatory and anti-inflammatory monocyte and macrophage subsets) involved in myocarditis and inflammatory cardiomyopathy. 


\section{Genetic testing and biomarkers}

Genetic testing. Monogenetic familial forms of acute myocarditis or chronic inflammatory cardiomyopathies are rare. Nevertheless, arrhythmogenic cardiomyopathies, in particular those caused by heterozygous pathogenic variants in $D S P$, have been associated with
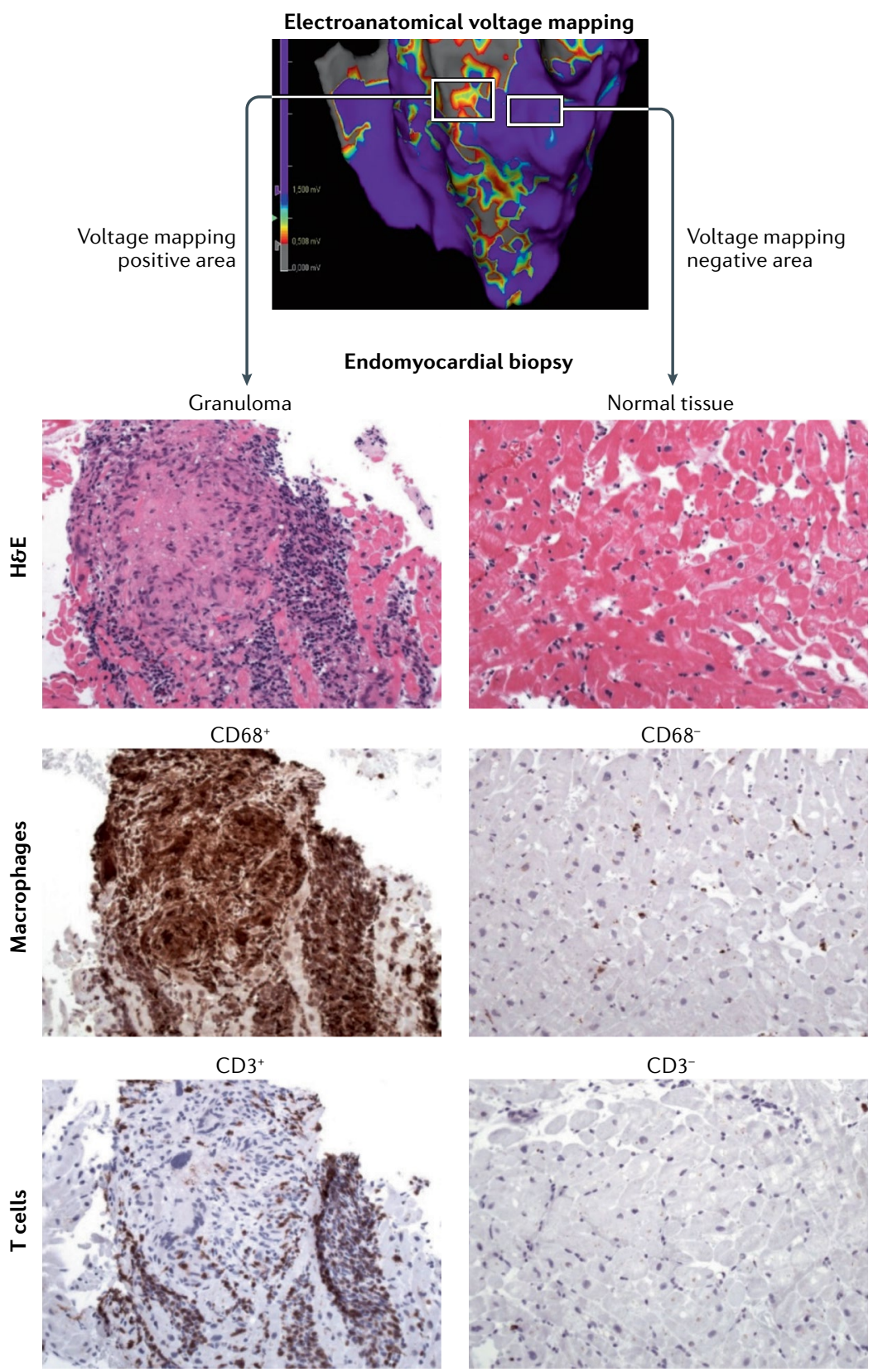

$\mathrm{CD} 20^{+}$
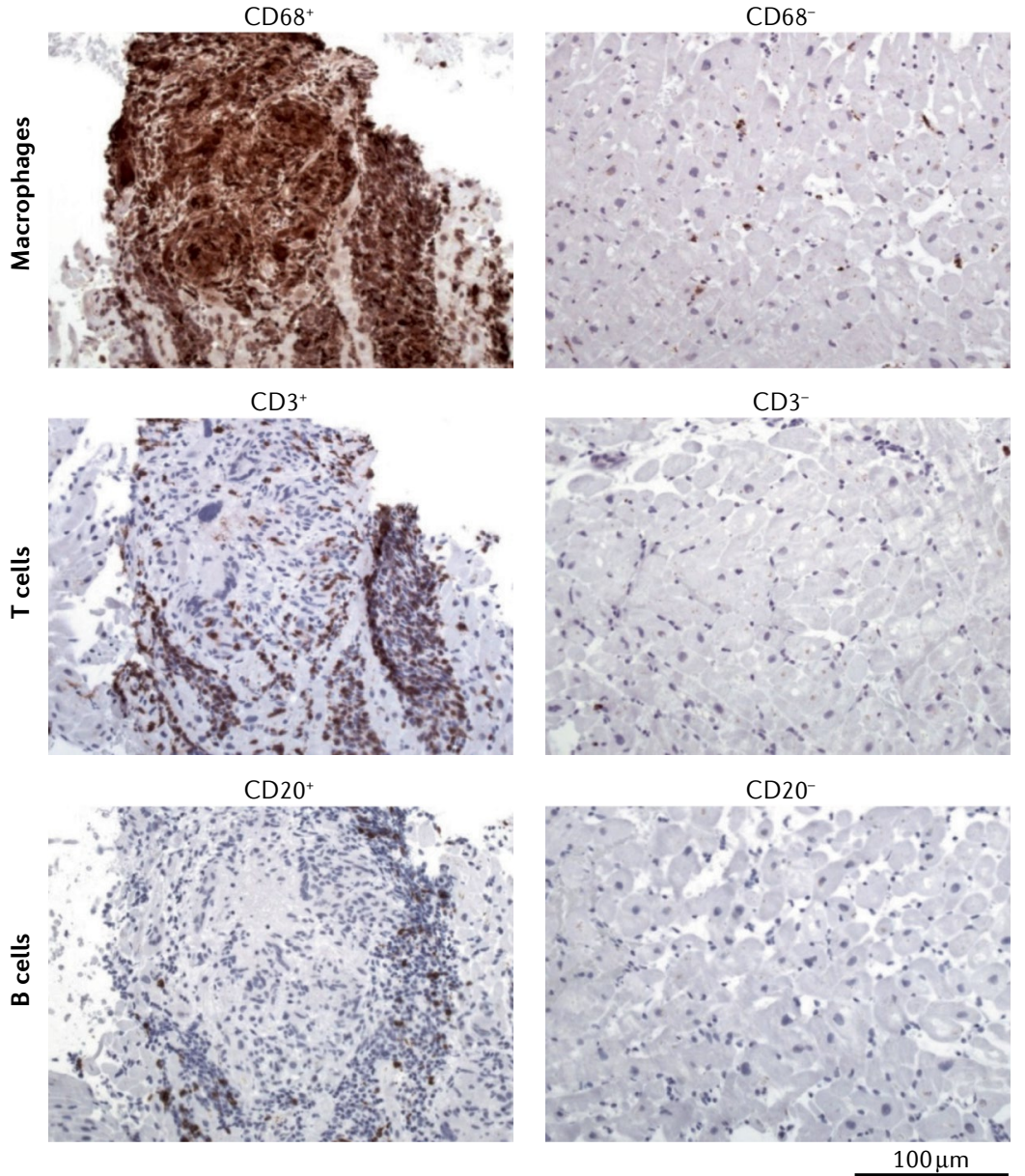

increased cardiac inflammation and a clinical presentation of acute myocarditis with elevated plasma troponin levels in addition to typical cardiac MRI or PET-CT scan abnormalities ${ }^{216-220}$. A homozygous but not heterozygous carrier state of rare variants in genes associated with inherited arrhythmogenic cardiomyopathies is significantly more frequent in children with acute myocarditis than in healthy individuals ${ }^{221}$. The mechanisms underlying the increased cardiac inflammation in arrhythmogenic cardiomyopathies remain unclear. Nevertheless, genetic testing should be considered in all familial forms of myocarditis, in familial cardiomyopathy or when signs of arrhythmogenic cardiomyopathy are present in imaging or electrophysiological tests.

MicroRNA profiling in EMB samples and blood. Epigenetic factors influence the expression of different genes and the genetic susceptibility to developing myocarditis and inflammatory cardiomyopathy. MicroRNAs (miRNAs) have emerged as important epigenetic regulators of the immune response in the heart ${ }^{222}$. Therefore, miRNA profiling of EMB samples might help distinguish different forms of myocarditis. For example, $107 \mathrm{miRNAs}$ were found to be differentially expressed in RV septal samples from patients with acute viral myocarditis compared with heart samples from control individuals ${ }^{223}$. Cardiac miRNA profiles also differ in patients with myocarditis with or without CVB3 persistence, whereby the expression of eight miRNAs was strongly increased in samples from patients with late viral persistence and progressive cardiac dysfunction compared with samples from patients with spontaneous virus clearance and cardiac recovery ${ }^{224}$. The expression of 113 of $641 \mathrm{miRNAs}$ analysed was significantly altered in heart samples from mice with Trypanosoma cruziinduced myocarditis compared with heart samples from control mice ${ }^{225}$. A study assessing heart-associated, fibrosis-associated and leukocyte-associated miRNAs in blood found that only miRNAs related to cardiomyocyte injury (including miR-208 and miR-499) were elevated in patients with acute myocarditis compared with control individuals ${ }^{226,227}$. However, these markers of cardiomyocyte injury are non-specific because they are also increased in patients with acute ischaemic or hypertensive cardiac events ${ }^{226,228}$. Interestingly, the plasma levels of miRNAs related to inflammation,

\section{Fig. 5 | Electroanatomical voltage mapping to guide}

endomyocardial biopsy. Identification of a myocardial scar area with the use of $3 \mathrm{D}$ electroanatomical voltage mapping in a patient with suspected cardiac sarcoidosis. The left square in the top panel marks a scar area identified by the presence of low voltages (red and yellow). Subsequent analysis of endomyocardial biopsy samples from this region identified the presence of a sarcoid granuloma in the scar area, visualized with haematoxylin and eosin staining (HEE), with the presence of $\mathrm{CD} 68^{+}$cells (macrophages), $\mathrm{CD} 3^{+}$cells ( $\mathrm{T}$ cells) and $\mathrm{CD} 2 \mathrm{O}^{+}$cells (B cells), as revealed by antibody staining (brown). By contrast, analysis of endomyocardial biopsy samples from a non-scar area, identified by high voltages (purple) in electroanatomical voltage mapping, showed normal tissue structure and no infiltration of immune cells. All histology images $\times 100$. 

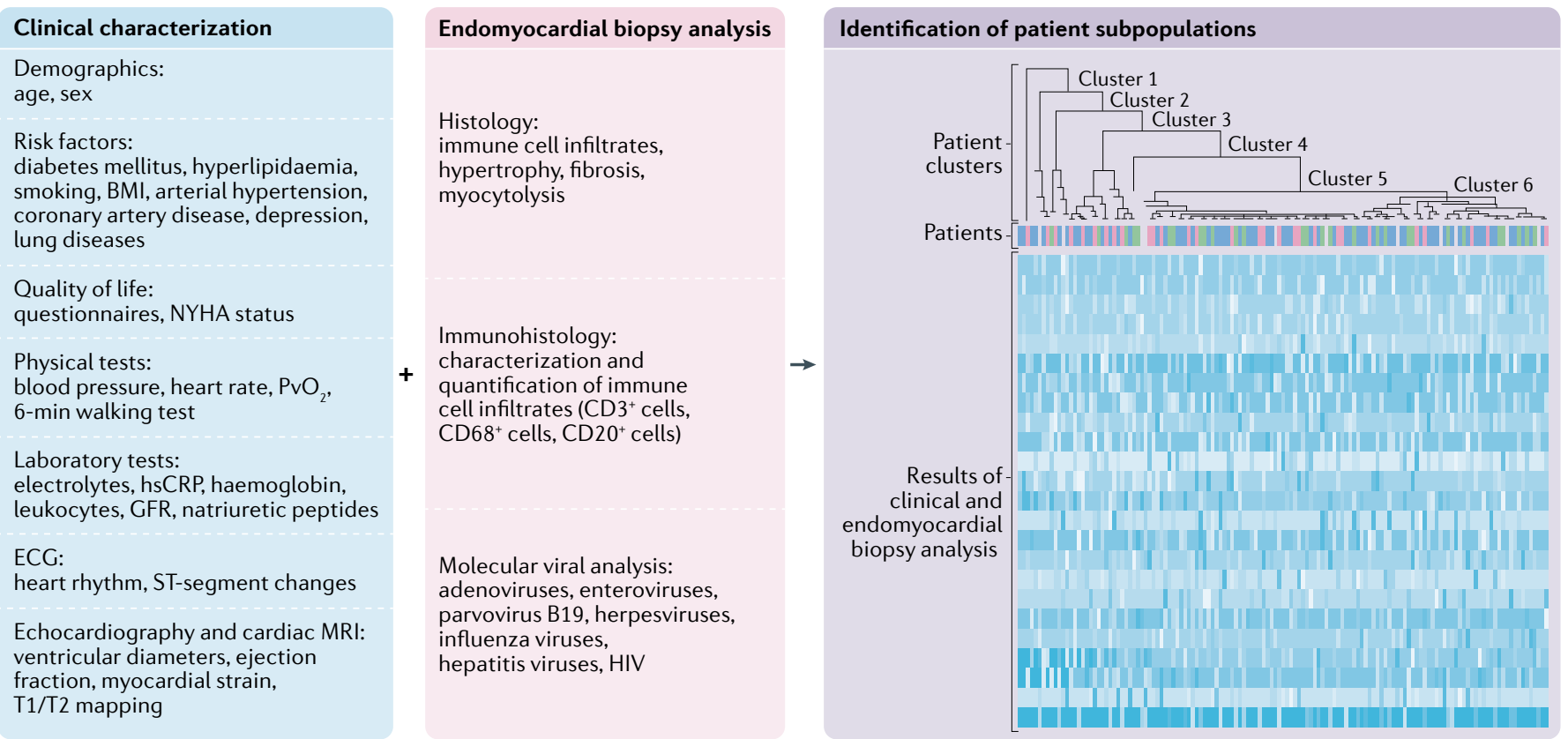

Fig. 6 | Improving the subclassification of patients with inflammatory cardiomyopathy. Clinical characterization of the patient (using risk factors and demographic and quality of life parameters, in addition to basic, physical and laboratory tests, and electrocardiography (ECG), echocardiography and cardiac MRI measurements) — known as phenomapping - combined with histology, immunohistology and viral diagnosis of endomyocardial biopsy samples will allow the classification of patients with inflammatory cardiomyopathy into different clusters, with the ultimate goal of defining therapeutically homogeneous patient subpopulations to improve outcomes. The figure shows a schematic example of a heatmap with hierarchical clustering of the patients on the basis of clinical parameters and endomyocardial biopsy results. GFR, glomerular filtration rate; HIV, human immunodeficiency virus; hsCRP, high-sensitivity C-reactive protein; $\mathrm{PvO}_{2}$, mixed venous oxygen tension.

including miR-21, miR-146b and miR-155, were not increased in patients with acute myocarditis compared with control individuals even though leukocyte counts were elevated ${ }^{226}$, which possibly reflects the absence of miRNA release by inflammatory cells. In general, the correlation between circulating and tissue miRNAs is not clear and needs further investigation. Future investigations to further profile miRNAs, mRNA and proteins should focus on both circulating leukocytes and EMB samples to provide a better reflection of disease pathophysiology. These studies might provide new ways to distinguish different forms of myocarditis as well as to differentiate between myocarditis and ischaemic injury, which is an important unmet medical need.

EMB transcriptome-based biomarker. In addition to miRNAs, a panel of mRNAs has been shown to be highly predictive of the presence or absence of lymphocytic myocarditis ${ }^{229}$. A microarray-derived, transcriptomebased biomarker had a $100 \%$ sensitivity and specificity for the detection of myocarditis in EMB samples ${ }^{229}$. The most parsimonious transcriptomic signature was highly enriched for immune markers, notably various members of the TLR family. This transcriptome-based biomarker effectively detected lymphocytic myocarditis and active cardiac inflammatory disease in EMB samples from patients with rheumatic disease or peripartum cardiomyopathy ${ }^{229}$. Work is ongoing to test this approach for liquid biopsy.
Blood biomarkers. In addition to EMB-based biomarkers, several blood biomarkers, including highsensitivity C-reactive protein, $\mathrm{N}$-terminal pro-B-type natriuretic peptide (NT-proBNP), troponin T and soluble IL-1 receptor-like 1 (IL1RL1; also known as ST2), have been studied in the context of myocarditis and inflammatory cardiomyopathy ${ }^{2,22,66}$. In men, but not in women, aged $\leq 50$ years with clinically suspected or EMB-confirmed myocarditis, elevated serum levels of soluble ST2 are associated with an increased risk of more severe HF, as assessed by NYHA class ${ }^{22}$. This finding highlights the potential of using soluble ST2 as a biomarker to predict the risk of HF in men and the importance of analysing inflammatory biomarkers such as soluble ST2 according to sex and age, and indicates the need for biomarkers that predict the risk of $\mathrm{HF}$ in women with myocarditis ${ }^{22}$. Myocarditisspecific blood biomarkers that can inform the diagnosis in patients with suspected myocarditis and can determine the presence or absence of active myocardial inflammation have not been established so far ${ }^{2,66}$. Preliminary evidence indicates that plasma levels of the S100A8-S100A9 heterodimer, which is predominantly released by monocytes and neutrophils, accurately reflect disease activity in cardiac tissue samples from patients with recent-onset myocarditis ${ }^{70}$. In addition, these preliminary data suggest that S100A8-S100A9 could serve as a diagnostic and therapy-monitoring biomarker in patients with suspected acute myocarditis $(\leq 30 \text { days after myocarditis onset })^{70}$. 
Patients with autoimmune myocarditis ${ }^{230}$ or idiopathic $\mathrm{DCM}^{231}$ have lower numbers of circulating $\mathrm{T}_{\text {reg }}$ cells and greater response of circulating $\mathrm{T}_{\mathrm{H}} 17$ cells than healthy individuals. Therefore, measuring blood $\mathrm{T}_{\text {reg }}$ cell and $\mathrm{T}_{\mathrm{H}} 17$ cell numbers in these patients might be beneficial in guiding therapeutic decisions and for therapy follow-up, given the availability of therapies that increase the $\mathrm{T}_{\text {reg }}$ cell to $\mathrm{T}_{\mathrm{H}} 17$ cell ratio. Inflammatory cardiomyopathy has been shown to be driven, at least in part, by the activation of heart-specific $\mathrm{CD} 4^{+} \mathrm{T}$ cells induced by myosin peptide mimics derived from Bacteroides thetaiotaomicron, an intestinal commensal bacterium. This finding suggests that the analysis of IgG antibodies specific for this gut bacterium species might help guide antibiotic treatment decisions ${ }^{141}$.

In the future, analysis of liquid biopsies might help dissect the high heterogeneity of cardiac tissue by providing information on circulating cell types (such as immune cells) and their products at specific time points, thereby allowing real-time monitoring of disease evolution. Use of innovative NGS platforms to analyse blood samples might help identify novel circulating biomarkers, including DNA methylation, histone modification and miRNA makers, as crucial pathogenic determinants of inflammatory heart diseases ${ }^{232}$. Another interesting approach is to evaluate whether the analysis of the proteome of exosomes present in serum can help identify the different types of myocarditis and whether exosomal protein analysis can be used for the development of predictive and prognostic biomarkers ${ }^{233}$.

\section{Knowledge gaps and future directions.}

- Understand why variants in DSP that are associated with arrhythmogenic cardiomyopathies have been associated with a clinical presentation of myocarditis on cardiac MRI scans.

- Develop myocarditis-specific blood biomarkers that can inform the diagnosis in patients with suspected myocarditis and help to determine the presence or absence of active myocarditis.

- Develop markers for therapy monitoring.

- Develop biomarkers that predict the risk of HF in women with myocarditis.

- Establish the reason for the lack of correlation between miRNAs levels in blood and in EMB samples.

- Determine whether potential markers that are developed on the basis of circulating cells would be more sensitive and specific in diagnosing and discriminating myocarditis from other causes than markers that are developed on the basis of EMB samples.

\section{Therapy}

\section{Management of HF and arrhythmias}

Patients with myocarditis and reduced LVEF are treated with optimal medical care, according to guidelines for the management of $\mathrm{HF}^{234}$. However, many patients with myocarditis have preserved LVEF. Whether early initiation of treatment with inhibitors of the reninangiotensin-aldosterone system or with $\beta$-blockers can reduce inflammation, adverse remodelling and scar formation in these patients is questionable. In particular, the risk of arrhythmia is increased in patients with myocarditis independently of $\mathrm{LVEF}^{235}$.

In patients with myocarditis, life-threatening bradyarrhythmias and tachyarrhythmias can occur at any stage of the disease and lead to sudden cardiac death ${ }^{155,236}$. Ventricular arrhythmias (VA) are mostly reported in patients with giant-cell myocarditis or cardiac sarcoidosis, with a prevalence of $29 \%{ }^{237}$ and $55 \%{ }^{238}$, respectively. Supraventricular arrhythmias occur more frequently than VA in patients with myocarditis and can vary in prevalence depending on the type of myocarditis ${ }^{239}$. Atrioventricular block is less common in patients with acute or fulminant myocarditis than in patients with cardiac sarcoidosis, and has a variable, but mostly low prevalence in patients with giant-cell myocarditis ${ }^{9}$. The frequency of cardiac electrical conductance disturbances decreases from giant-cell myocarditis to eosinophilic myocarditis to lymphocytic myocarditis ${ }^{240}$. The high prevalence of cardiac electrical conductance disturbances in patients with myocarditis highlights a clinical need to identify patients with myocarditis at risk of arrhythmia, independently of LVEF and LGE.

Several pathogenic mechanisms have been postulated to explain the presence of different arrhythmias observed in patients with acute myocarditis, including electrical instability due to direct cytopathic effects, ischaemia due to coronary microvascular or macrovascular disease, gap junction dysfunction, abnormal calcium handling and involvement of the cardiac conduction system. The risk of sudden cardiac death in patients with acute myocarditis is not always associated with the severity of myocardial inflammation $^{241}$, and can persist after the acute phase of myocarditis is resolved ${ }^{13}$. Post-inflammatory, scar-related VA can present as monomorphic ventricular tachycardia in patients with healed myocarditis ${ }^{242}$. Post-inflammatory scar-related VA occurs in regions of myocardial fibrosis, which appear as low-voltage regions on electroanatomical voltage mapping or as LGE on cardiac MRI. Although systolic dysfunction is a common finding in patients with myocarditis with VA, an arrhythmogenic scar can occur in patients with preserved $\mathrm{LVEF}^{13}$. EMB is recommended for the diagnosis of myocarditis in patients with VA and acute cardiomyopathy because the risk of VA is increased in patients with inflammation in EMB samples ${ }^{241}$ (TABLE 2). The presence of viral nucleic acids in EMB samples can also indicate an increased risk of VA and late myocardial damage with progressive electrical conduction defects. In a mouse model of CVB3-induced myocarditis, modulating, time-dependent effects of the CVB3 infection were found in the cardiac ion channels KCNQ1, hERG1 and $\mathrm{Ca}_{\mathrm{v}} 1.2$ in heterologous expression, providing an explanation for the development of arrhythmias in enteroviral myocarditis ${ }^{243}$. Given that EMB for the diagnosis of cardiac inflammation in patients with VA can have a high sampling error in patients with focal myocarditis and especially in patients with cardiac sarcoidosis, electroanatomical voltage mapping can be used to target the bioptome (the instrument used to obtain EMB samples) to areas with $<0.5 \mathrm{mV}$ amplitude and fractionated electrogram signal ${ }^{201-204}$ (FIC. 5). 
Immunoadsorption

Selective apheresis method

for the removal of specific

antibodies and immune

complexes through high-

affinity adsorbers, achieved

by passing a patient's plasma

over columns that remove

immunoglobulins. The

adsorbed plasma is then

reinfused into the patient.

Intravenous

immunoglobulin

(IVIG). Therapy based on the

intravenous administration of a

blood product prepared from

the serum of 1,000-15,000

donors per batch. IVIC therapy

is the treatment of choice

for patients with antibody

deficiencies and is commonly

used after immunoadsorption.
Symptomatic VA in patients with acute myocarditis is usually managed with antiarrhythmic drugs, but the efficacy of this approach has not been tested. Cardiac device implantation for the management of VA should be evaluated after the resolution of reversible acute myocarditis, generally 3-6 months after initiation of the acute phase ${ }^{244}$. However, the timings for the placement of an implantable cardioverter-defibrillator (ICD) remain unclear. Temporary pacing might be required on presentation, but decisions for chronic pacing typically require a period of observation, histological examination of EMB samples and assessment of the disease course. Early de novo ICD implantation in patients with reduced LVEF alone should be avoided, and the use of a wearable cardioverter-defibrillator (LifeVest, ZOLL) should be considered in patients at high risk of sudden cardiac death $^{245}$, in patients with lymphocytic myocarditis and in patients with myocarditis and VA in the acute phase of disease $\mathrm{e}^{246}$. Nevertheless, the best timing of wearable cardioverter-defibrillator use has not been prospectively investigated. Patients with giant-cell myocarditis and VA with a heart transplant-free life expectancy of $>1$ year should receive an ICD. Risk management in patients with cardiac sarcoidosis is most probably independent of LVEF, indicating that LVEF-independent markers need to be identified.

\section{Knowledge gaps and future directions.}

- Assess the role of classic HF medications for the primary prevention of HF in patients with myocarditis.

- Characterize the role of LVEF for predicting the risk of sudden death in patients with myocarditis.

- Assess the influence of the different forms of inflammatory cardiomyopathy on the risk of sudden cardiac death (for example, cardiac sarcoidosis versus lymphocytic myocarditis).

- Assess the best timing for cardiac pacing device implantation.

- Investigate the role of a wearable cardioverterdefibrillator in patients with myocarditis with preserved LVEF and with signs of clinically significant cardiac rhythm abnormalities.

- Develop a patient stratification model for the risk of sudden death in patients with myocarditis.

- Perform clinical trials to assess the efficacy of antiarrhythmic drugs in patients with cardiac inflammation.

- Investigate the effect of (intensive) exercise on the propensity to sudden cardiac death and $\mathrm{HF}^{247}$.

\section{Drugs and biologics}

Several treatment options have been studied in specific cohorts of patients with inflammatory cardiomyopathy that have been developed on the basis of the EMB-defined presence of viral genome (virus type and viral load) and immune cell infiltrates.

Virus-negative inflammatory cardiomyopathy. Studies and registries of EMB samples from patients with virusnegative, chronic inflammatory cardiomyopathy suggest that the use of immunosuppressive therapy with prednisone and azathioprine can improve cardiac function ${ }^{127,128,248,249}$. These findings contrast with results from earlier studies in patients with acute cardiomyopathy in which viral pathogens were not assessed. A single-centre, observational study found that $53 \%$ of patients with inflammatory cardiomyopathy who do not respond to steroid-based therapy had $\mathrm{CD} 20^{+} \mathrm{B}$ cells in EMB samples ${ }^{114}$. In this subset of six patients with virusnegative inflammatory cardiomyopathy and CD20+ $\mathrm{B}$ cell-positive EMB results, treatment with rituximab (a chimaeric monoclonal antibody against the pan-B cell surface molecule CD20) improved cardiac function and alleviated signs and symptoms of HF from baseline ${ }^{114}$, suggesting that rituximab therapy has beneficial effects in this patient population. Alternative treatment regimens for patients with virus-negative or autoimmune inflammatory cardiomyopathy include steroid-based treatment combined with cyclosporine $e^{250}$ or mycophenolate mofetil ${ }^{251}$, or immunoadsorption with subsequent intravenous immunoglobulin (IVIG) therapy ${ }^{252-254}$ (immunoadsorption-IVIG). Removal of circulating antibodies by non-specific immunoadsorption has been successful in the treatment of several autoimmune diseases ${ }^{255,256}$. Pilot studies indicate that immunoadsorption-IVIG improves myocardial function in patients with $\mathrm{DCM}^{252}$ and reduces myocardial inflammation ${ }^{257}$. However, these novel findings should be viewed as hypothesis-generating and more data are required from randomized trials. Indeed, a large, placebo-controlled multicentre study to investigate the effects of immunoadsorption-IVIG on LV function in patients with DCM or inflammatory cardiomyopathy is ongoing ${ }^{258}$. The randomization phase of this study was completed in 2019. An alternative to immunoadsorption is the intravenous administration of small soluble molecules (such as peptides or aptamers) that specifically target and neutralize autoantibodies against the $\beta_{1}$-adrenergic receptor ${ }^{259}$. Of note, the use of antibodytargeting approaches does not depend on the presence of cardiac inflammation (FIG. 7).

Virus-positive inflammatory cardiomyopathy. Differentiating between virus-induced active myocarditis (for example, caused by adenoviruses or enteroviruses) and virus-associated myocarditis (in which the viral genome is detected in EMB samples but whether the virus is a bystander is not clear; for example, caused by latent infections with herpesviruses or B19V) is important (FIG. 7). To date, the therapeutic efficacy of targeting the viral infection in acute viral myocarditis has not yet been established in randomized clinical trials. The phase II BICC trial ${ }^{260}$ investigated the effects of immunomodulation with IFN $\beta$ therapy on viral clearance in patients with inflammatory cardiomyopathy and myocardial viral persistence (adenoviruses, enteroviruses or B19V). Trial participants with enteroviruspositive myocarditis or adenovirus-positive myocarditis (as assessed with EMB) showed viral clearance after treatment with IFN $\beta^{26,260}$, but IFN $\beta$ therapy was not associated with viral DNA clearance in patients with B19V-positive myocarditis ${ }^{146,260}$. The antiviral drugs pocapavir and pleconaril as well as IVIG therapy are effective in neonates with enteroviral myocarditis ${ }^{15-17}$. In patients with latent infection with Epstein-Barr virus, 
patients with influenza-associated myocarditis ${ }^{267,268}$. For patients with COVID-19, several antiviral regimens are under investigation and include strategies to prevent viral entry into the host cell (such as chloroquine, hydroxychloroquine, camostat mesylate and umifenovir), protease inhibitors (lopinavirritonavir and darunavir), RNA polymerase inhibitors (remdesivir) and anti-cytokine agents (such as IL-6 receptor antagonists and IL- $1 \beta$ inhibitors ${ }^{269}$.

\section{Knowledge gaps and future directions.}

- Perform large, prospective, randomized controlled studies to explore new or existing (repurposed) immunosuppressive or immunomodulatory regimens and antiviral regimens in patients with myocarditis or inflammatory cardiomyopathy.

- Perform multicentre, EMB-guided or cardiac MRIguided trials to assess optimal treatment duration with conventional HF drugs and, particularly, with treatment regimens that still need to be approved for clinical use.

- Perform sex-matched clinical studies, given the wellknown sex-related differences in immune responses ${ }^{21,22}$ and outcomes in patients with myocarditis ${ }^{270}$.

\section{Novel therapeutic strategies}

Patients who do not respond to guideline-directed neurohormonal inhibitor therapy and haemodynamic support might benefit from therapies that either inhibit one or more of the effector arms of the immune response or promote regulatory elements of the immune system. Insights from exploratory clinical trials suggest that multiple signalling pathways can be differentially activated in patients with myocarditis or inflammatory cardiomyopathy. Importantly, current clinical trials are designed on the basis of lessons learned from previous trials on high-dose TNF inhibitor therapy in patients with systolic HF, which did not show improvements in patient outcomes ${ }^{271}$. By taking a systematic approach to personalize targeted therapies, the current generation of therapeutic agents are aimed at minimizing toxicity and maximizing the likelihood of recovery in patients with specific phenotypes of inflammatory cardiomyopathy.

Soluble anti-CAR antibody. Treatment with an engineered soluble CAR fused to the carboxy terminus of human IgG, which reduces virus uptake into host cells, has been shown to limit the development of acute ${ }^{272}$ and chronic ${ }^{273}$ CVB3-induced myocarditis in mice. The potential of this approach still needs to be evaluated in humans.

Anti-IL-1 $\beta$ and anti-IL-1 receptor antibodies. Findings from studies in animal models of viral and autoimmune myocarditis support a central role for NLRP3 inflammasome activation and subsequent IL- $1 \beta$ production in the pathogenesis of myocarditis ${ }^{68,274}$. Treatment with an anti-mouse IL- $1 \beta$ antibody at different stages of enteroviral infection prevented the development of chronic viral myocarditis by reducing inflammation, interstitial fibrosis and adverse cardiac remodelling in mice $^{274}$. One clinical trial ${ }^{275}$ and several case series ${ }^{276,277}$ support the use of an anti-IL-1 $\beta$ monoclonal antibody for the treatment of recurrent pericarditis. The ongoing ARAMIS $^{278}$ and RHAPSODY ${ }^{279}$ trials are designed to assess the efficacy of IL- $1 \beta$-blocking agents in patients with myocarditis and associated pericarditis.

Anti-IL-17 antibody. Increased IL-17-related responses and the activation of profibrotic pathways have been associated with a greater risk of death in mice with CVB3-induced myocarditis ${ }^{280}$ and with a lower rate of functional recovery in patients with myocarditis ${ }^{108}$. $\mathrm{T}_{\mathrm{H}} 17$ cells have been shown to promote the progression to DCM in mice ${ }^{102}$, whereas $\mathrm{T}_{\text {reg }}$ cells protected against myocarditis in mice by attenuating inflammation ${ }^{80,103}$. A clinical trial of secukinumab, an anti-IL-17 monoclonal antibody, has been proposed.

Cell-based therapies. Clinical application of $\mathrm{T}_{\mathrm{reg}}$ cells $\mathrm{s}^{281}$ or the use of IL-2 agonists ${ }^{282}$ (which promote $\mathrm{T}_{\text {reg }}$ cell production and increase survival and suppressor function of mature $\mathrm{T}_{\text {reg }}$ cells $^{283}$ ) are alternative approaches to elevate the $\mathrm{T}_{\text {reg }}$ cell to $\mathrm{T}_{\mathrm{H}} 17$ cell ratio. Another potential cell-based approach involves the use of mesenchymal stromal cells, which have been shown to increase the number of $\mathrm{T}_{\text {reg }}$ cells ${ }^{85}$ and have immunomodulatory and cardioprotective effects in mouse models of myocarditis ${ }^{69,78,284}$, such as by modulating the cardiosplenic axis. Therapy with allogeneic mesenchymal stromal cells has also been shown to be safe and effective in patients with non-ischaemic DCM in the POSEIDONDCM trial ${ }^{285}$. In this trial, a significant improvement in LVEF with autologous mesenchymal stromal cell therapy was observed only in patients who did not carry a pathogenic gene variant associated with DCM, indicating the relevance of the genetic profile of patients with non-ischaemic DCM in dictating responsiveness to mesenchymal stromal cell therapy ${ }^{286}$. This response was associated with a marked reduction in circulating TNF levels ${ }^{285}$, suggestive of a therapeutic effect governed by immunomodulation. Taken together, these findings indicate that cell-based therapy has a potential role in the treatment of patients with inflammatory cardiomyopathy. Future trials are warranted to test this hypothesis.

Aldosterone antagonists. Evidence shows that early blockade (starting at the acute phase of CVB3 infection) of the mineralocorticoid receptor with eplerenone has pleiotropic effects, including immunomodulatory, anti-oxidative and anti-apoptotic effects, and prevents adverse cardiac remodelling and dysfunction without affecting viral load in the heart in a mouse model of persistent viral myocarditis ${ }^{287}$. This finding suggests that eplerenone is an ideal candidate as an acute treatment of myocarditis, together with HF treatment. However, current guidelines do not consider aldosterone antagonist therapy for acute myocarditis, indicating the need to test this new therapeutic concept in clinical trials.

Cannabidiol and antagomirs. Interventions that primarily promote regulatory functions of the immune system for the treatment of myocarditis are under investigation 
in experimental models. The approaches include therapy with cannabidiol ${ }^{288}$ and therapy with antisense miRNA complements $^{71}$ (known as antagomirs or anti-miRs). Antagomirs injected systemically or locally can be used as a therapeutic tool to reduce either inflammation or virus replication ${ }^{71}$.

Modulation of the gut microbiome. Accumulating findings demonstrate the contribution of the gut microbiome and its derived metabolites to the underlying inflammation associated with $\mathrm{HF}^{289}$. In addition, a gut microbiota-derived myosin-mimic peptide has been linked to inflammatory cardiomyopathy ${ }^{141}$. These findings suggest that modulation of the microbiome and its derived metabolites are potential preventive and therapeutic strategies for inflammatory heart diseases.

Mechanical circulatory support in patients with fulminant myocarditis. In patients with cardiogenic shock due to fulminant myocarditis, parenteral inotropes and short-term MCS systems are often required. MCS can be used regardless of initiation of immunosuppressive therapy. Different MCS devices are effective for temporary haemodynamic stabilization and can serve as a bridgeto-transplant in patients with fulminant myocarditis, including veno-arterial extracorporeal membrane oxygenation (V-A ECMO ${ }^{290,291}$, intra-aortic balloon pumps (IABPs) ${ }^{291,292}$, the percutaneous ventricular assist devices TandemHeart ${ }^{291}$ and ProtekDuo ${ }^{293}$, and the Impella microaxial flow catheters ${ }^{291,292,294}$. These devices differ in their mode of action, especially their effect on afterload modification. The effect of these devices on afterload modification might be of special interest in fulminant myocarditis, because a rise in peripheral resistance can also further stimulate cardiac inflammatory responses owing to an increase in ventricular wall stress. The high flow of V-A ECMO is known to increase LV afterload, which has been suggested to trigger cardiac inflammatory responses and unfavourable cardiac remodelling over time. IABP and TandemHeart have a minimal effect on LV afterload reduction, whereas intravascular aortic catheter (iVAC) and, even more effective, LV Impella microaxial flow catheter systems (the Impella CP, 5.0 and 5.5) support peripheral circulation in combination with ventricular unloading ${ }^{295}$. Mechanical load has been shown to activate the cardiac mechanotransduction network ${ }^{296}$, which is associated with unfavourable cardiac remodelling and cardiac fibroblast activation, and further promotion of inflammatory processes ${ }^{297}$. Evidence from LV assist devices in patients with chronic HF indicates that mechanical unloading can lead to reverse remodelling involving immunomodulatory mechanisms ${ }^{298,299}$. According to first single-centre studies, prolonged use of microaxial flow catheters over weeks exerts unique anti-inflammatory, disease-modifying effects beyond circulatory support (PROPELLA concept) (25,300. $^{2}$.

In routine clinical practice, the choice of MCS device usually depends on its availability at the centre and on whether the left or right ventricle alone, or both, are compromised. Patients with primarily RV or biventricular failure are usually treated with an extracorporeal centrifugal flow-based regimen (V-A ECMO, iVAC, TandemHeart and ProtekDuo $)^{291}$. Analyses of data from experienced centres show that the combination of a V-A ECMO with an IABP, an iVAC (EC-iVAC) or LV Impella (ECMELLA) is safe and probably more effective than a single V-A ECMO approach in patients with fulminant myocarditis ${ }^{292,301,302}$. Fewer data are available on the efficacy of the RP Impella system and/or its combination with the LV Impella in unloading both ventricles (BIPELLA-concept) in patients with fulminant myocarditis ${ }^{300,303}$. In patients with primarily LV failure and preserved RV function, use of the LV Impella system for unloading might be favourable ${ }^{159,294,295,300}$. More research is needed to understand the mechanisms underlying the anti-inflammatory effects of prolonged LV unloading (PROPELLA concept) ${ }^{295}$ with the use of percutaneous LV support devices, which can serve as a bridge-to-recovery or bridge-to-transplant. Furthermore, clinical trials are needed to validate the PROPELLA concept, preferably including EMB analysis. Furthermore, the question of whether pulsatile systems (such as iVAC and IABPs) differ from non-pulsatile systems needs to be answered.

\section{Knowledge gaps and future directions.}

- Generate prospective data from multicentre registries to assess standardized protocols that can guide the management of patients with fulminant myocarditis or acute myocarditis complicated by severe HF.

- Identify the best MCS or combination of MCS that allow optimal perfusion and LV unloading.

- Perform randomized clinical trials to assess the efficacy of immunosuppressive treatments for patients with fulminant myocarditis receiving MCS.

\section{Conclusions}

Myocarditis and inflammatory cardiomyopathy were first defined in the early $1900 \mathrm{~s}^{304}$. Since then, milestone discoveries (including the technique of $\mathrm{EMB}^{305}$, the invention of PCR and the development of cardiac $\mathrm{MRI}^{306}$ ) and consensus statements have led to a refined definition of myocarditis and inflammatory cardiomyopathy, with the latest major update published in $2013\left(\mathrm{REF}^{2}\right)$. This timeline renders the field of myocarditis and inflammatory cardiomyopathy as a fairly young area in cardiology. Entering the 2020s, gaps remain in our understanding of the pathogenesis of, and the diagnostic and therapeutic options for, myocarditis and inflammatory cardiomyopathy. The availability of novel sophisticated techniques, emerging and existing (repurposed) therapies, computational modelling and novel insights will help address these knowledge gaps in the near future. Specific diagnostic approaches for different clinical scenarios will help improve the subclassification of patients with inflammatory cardiomyopathy, and improve the common terminology in a field that is not completely univocal. Finally, the efficacy of many existing, repurposed or emerging therapies needs to be evaluated in large, controlled, randomized trials to facilitate the development of aetiology-based therapies ${ }^{159}$ (FIG. 7).

Published online 12 October 2020 
1. Richardson, P. et al. Report of the 1995 World Health Organization/International Society and Federation of Cardiology task force on the definition and classification of cardiomyopathies. Circulation 93 841-842 (1996)

2. Caforio, A. L. et al. Current state of knowledge on aetiology, diagnosis, management, and therapy of myocarditis: a position statement of the European Society of Cardiology Working Group on Myocardial and Pericardial Diseases. Eur. Heart J. 34, 2636-2648 (2013)

3. Ammirati, E. et al. Clinical presentation and outcome in a contemporary cohort of patients with acute myocarditis. Circulation 138, 1088-1099 (2018).

4. Kociol, R. D. et al. Recognition and initial management of fulminant myocarditis: a scientific statement from the American Heart Association. Circulation 141 e69-e92 (2020)

5. Ammirati, E. et al. Fulminant versus acute nonfulminant myocarditis in patients with left ventricular systolic dysfunction. J. Am. Coll. Cardiol. 74, 299-311 (2019).

6. Dominguez, F., Kuhl, U., Pieske, B., Garcia-Pavia, P. \& Tschöpe, C. Update on myocarditis and inflammatory cardiomyopathy: reemergence of endomyocardial biopsy. Rev. Esp. Cardiol. 69, 178-187 (2016).

7. Trachtenberg, B. H. \& Hare, J. M. Inflammatory cardiomyopathic syndromes. Circ. Res. 121, 803-818 (2017).

8. Hu, J. R. et al. Cardiovascular toxicities associated with immune checkpoint inhibitors. Cardiovasc. Res. 115, 854-868 (2019).

9. Caforio, A. L. P. et al. Diagnosis and management of myocardial involvement in systemic immune-mediated diseases: a position statement of the European Society of Cardiology Working Group on Myocardial and Pericardial Disease. Eur. Heart J. 38, 2649-2662 (2017).

10. Kuhl, U. et al. High prevalence of viral genomes and multiple viral infections in the myocardium of adults with "idiopathic" left ventricular dysfunction. Circulation 111, 887-893 (2005)

11. Ukimura, A., Satomi, H., Ooi, Y. \& Kanzaki, Y. Myocarditis associated with influenza A H1N1pdm2009. Influenza Res. Treat. 2012 351979 (2012).

12. Van Linthout, S., Klingel, K. \& Tschope, C. SARS-CoV2related myocarditis-like syndroms: Shakespeare's question: What's in a name? Eur. J. Heart Fail. 22 922-925 (2020)

13. Bozkurt, B. et al. Current diagnostic and treatment strategies for specific dilated cardiomyopathies: a scientific statement from the American Heart Association. Circulation 134, e579-e646 (2016)

14. Pauschinger, $\mathrm{M}$. et al. Detection of adenoviral genome in the myocardium of adult patients with idiopathic left ventricular dysfunction. Circulation 99, 1348-1354 (1999).

15. Yen, M. H. et al. Effect of intravenous immunoglobulin for neonates with severe enteroviral infections with emphasis on the timing of administration. J. Clin. Virol. 64, 92-96 (2015).

16. Abzug, M. J. et al. A randomized, double-blind, placebocontrolled trial of pleconaril for the treatment of neonates with enterovirus sepsis. J. Pediatric Infect. Dis. Soc. 5, 53-62 (2016).

17. Amdani, S. M. et al. Successful treatment of fulminant neonatal enteroviral myocarditis in monochorionic diamniotic twins with cardiopulmonary support, intravenous immunoglobulin and pocapavir. BMJ Case Rep. 2018, bcr-2017-224133 (2018)

18. Woodruff, J. F. Viral myocarditis. A review. Am. J. Pathol 101, 425-484 (1980)

19. Smith, W. G. Coxsackie B myopericarditis in adults. Am. Heart J. 80, 34-46 (1970)

20. Zhou, F. et al. Clinical course and risk factors for mortality of adult inpatients with COVID-19 in Wuhan, China: a retrospective cohort study. Lancet 395 , 1054-1062 (2020)

21. Frisancho-Kiss, $\mathrm{S}$. et al. Cutting edge: cross-regulation by TLR4 and T cell Ig mucin-3 determines sex differences in inflammatory heart disease. J. Immunol. 178, 6710-6714 (2007)

22. Coronado, M. J. et al. Elevated sera SST2 is associated with heart failure in men $\leq 50$ years old with myocarditis. J. Am. Heart Assoc. 8, e008968 (2019).

23. He, Y. et al. Interaction of coxsackievirus B3 with the full length coxsackievirus-adenovirus receptor Nat. Struct. Biol. 8, 874-878 (2001).

24. Badorff, C. et al. Enteroviral protease $2 \mathrm{~A}$ cleaves dystrophin: evidence of cytoskeletal disruption in an acquired cardiomyopathy. Nat. Med. 5, 320-326 (1999).

25. Lassner, D. et al. CCR5del32 genotype in human enteroviral cardiomyopathy leads to spontaneous virus clearance and improved outcome compared to wildtype CCR5. J. Trans/ Med. 16, 249 (2018).

26. Kuhl, U., Lassner, D., von Schlippenbach, J., Poller, W. $\&$ Schultheiss, H. P. Interferon-beta improves survival in enterovirus-associated cardiomyopathy. J. Am. Coll. Cardiol. 60, 1295-1296 (2012).

27. Leveque, N. et al. Functional consequences of RNA 5 '-terminal deletions on coxsackievirus B3 RNA replication and ribonucleoprotein complex formation. J. Virol. 91, e00423-17 (2017)

28. Bouin, A. et al. Enterovirus persistence in cardiac cells of patients with idiopathic dilated cardiomyopathy is linked to 5' terminal genomic RNA-deleted viral populations with viral-encoded proteinase activities. Circulation 139, 2326-2338 (2019).

29. Maisch, B. Cardio-immunology of myocarditis: focus on immune mechanisms and treatment options. Front. Cardiovasc. Med. 6, 48 (2019).

30. Manaresi, E. \& Gallinella, G. Advances in the development of antiviral strategies against parvovirus B19. Viruses 11, 659 (2019).

31. Duechting, A. et al. Human parvovirus B19 NS1 protein modulates inflammatory signaling by activation of STAT3/PIAS3 in human endothelial cells. J. Virol. 82, 7942-7952 (2008)

32. Van Linthout, S. et al. Telbivudine in chronic lymphocytic myocarditis and human parvovirus B19 transcriptional activity. ESC. Heart Fail. 5, 818-829 (2018).

33. Bultmann, B. D., Sotlar, K. \& Klingel, K. Parvovirus B19. N. Engl. J. Med. 350, 2006-2007 (2004).

34. Kindermann, I. et al. Predictors of outcome in patients with suspected myocarditis. Circulation 118, 639-648 (2008).

35. Hjalmarsson, C. et al. Parvovirus B19 in endomyocardial biopsy of patients with idiopathic dilated cardiomyopathy: foe or bystander? J. Card. Fail. 25, 60-63 (2019)

36. Schenk, T., Enders, M., Pollak, S., Hahn, R. \& Huzly, D. High prevalence of human parvovirus B19 DNA in myocardial autopsy samples from subjects without myocarditis or dilative cardiomyopathy. J. Clin. Microbiol. 47, 106-110 (2009).

37. Lotze, U. et al. Low level myocardial parvovirus B19 persistence is a frequent finding in patients with heart disease but unrelated to ongoing myocardial injury. J. Med. Virol. 82, 1449-1457 (2010)

38. Koepsell, S. A., Anderson, D. R. \& Radio, S. J. Parvovirus B19 is a bystander in adult myocarditis. Cardiovasc. Pathol. 21, 476-481 (2012).

39. Bock, C. T., Klingel, K. \& Kandolf, R. Human parvovirus B19-associated myocarditis. N. Engl. J. Med. 362, 1248-1249 (2010)

40. Bock, C. T. et al. Molecular phenotypes of human parvovirus B19 in patients with myocarditis. World J. Cardiol. 6, 183-195 (2014).

41. Dennert, R. et al. Differences in virus prevalence and load in the hearts of patients with idiopathic dilated cardiomyopathy with and without immune-mediated inflammatory diseases. Clin. Vaccine Immunol. 19 , 1182-1187 (2012)

42. Kuhl, U. et al. A distinct subgroup of cardiomyopathy patients characterized by transcriptionally active cardiotropic erythrovirus and altered cardiac gene expression. Basic. Res. Cardiol. 108, 372 (2013).

43. Richter, J. et al. An unusual presentation of a common infection. Infection 41, 565-569 (2013).

44. Kaufer, B. B. \& Flamand, L. Chromosomally integrated HHV-6: impact on virus, cell and organismal biology. Curr. Opin. Virol. 9, 111-118 (2014).

45. Barbaro, G. HIV-associated cardiomyopathy etiopathogenesis and clinical aspects. Herz 30 486-492 (2005)

46. Sanchez, M. J. \& Bergasa, N. V. Hepatitis C associated cardiomyopathy: potential pathogenic mechanisms and clinical implications. Med. Sci. Monit. 14 RA55-RA63 (2008).

47. Kumar, K. et al. Influenza myocarditis and myositis: case presentation and review of the literature Can $\mathrm{J}$. Cardiol. 27, 514-522 (2011).

48. Zhang, S. F. et al. Epidemiology characteristics of human coronaviruses in patients with respiratory infection symptoms and phylogenetic analysis of HCoV-OC43 during 2010-2015 in Guangzhou. PLOS ONE 13, e0191789 (2018)

49. Cui, J., Li, F. \& Shi, Z. L. Origin and evolution of pathogenic coronaviruses. Nat. Rev. Microbiol. 17, 181-192 (2019).
50. Zhou, P. et al. A pneumonia outbreak associated with a new coronavirus of probable bat origin. Nature. 579, 270-273 (2020)

51. Wang, D. et al. Clinical characteristics of 138 hospitalized patients with 2019 novel coronavirusinfected pneumonia in Wuhan, China. JAMA 323 1061-1069 (2020).

52. Zheng, Y. Y., Ma, Y. T., Zhang, J. Y. \& Xie, X. COVID-19 and the cardiovascular system. Nat. Rev. Cardiol. 17 259-260 (2020).

53. Huang, C. et al. Clinical features of patients infected with 2019 novel coronavirus in Wuhan, China. Lancet 395, 497-506 (2020).

54. Moore, B. J. B. \& June, C. H. Cytokine release syndrome in severe COVID-19. Science 368 . 473-474 (2020).

55. Guo, J., Huang, Z., Lin, L. \& Lv, J. Coronavirus disease 2019 (COVID-19) and cardiovascular disease: a viewpoint on the potential influence of angiotensinconverting enzyme inhibitors/angiotensin receptor blockers on onset and severity of severe acute respiratory syndrome coronavirus 2 infection. J. Am. Heart Assoc. 9, e016219 (2020).

56. Santos, R. A. S. et al. The ACE2/angiotensin-(1-7)/MAS axis of the renin-angiotensin system: focus on angiotensin-(1-7). Physiol. Rev. 98, 505-553 (2018).

57. Oudit, G. Y. et al. SARS-coronavirus modulation of myocardial ACE2 expression and inflammation in patients with SARS. Eur. J. Clin. Invest. 39, 618-625 (2009).

58. Li, W. et al. Receptor and viral determinants of SARS coronavirus adaptation to human ACE2, EMBO J. 24 1634-1643 (2005).

59. Hoffmann, M. et al. SARS-CoV-2 cell entry depends on ACE2 and TMPRSS2 and is blocked by a clinically proven protease inhibitor. Cell 181, 271-280 (2020).

60. Glowacka, I. et al. Evidence that TMPRSS2 activates the severe acute respiratory syndrome coronavirus spike protein for membrane fusion and reduces vira control by the humoral immune response. J. Virol. 85 4122-4134 (2011).

61. Nicin, L. et al. Cell type-specific expression of the putative SARS-CoV-2 receptor ACE2 in human hearts. Eur. Heart J. 41, 1804-1806 (2020)

62. Tavazzi, G. et al. Myocardial localization of coronavirus in COVID-19 cardiogenic shock. Eur. J. Heart Fail. 22. 911-915 (2020).

63. Varga, Z. et al. Endothelial cell infection and endotheliitis in COVID-19. Lancet 395, 1417-1418 (2020).

64. Forbes, J. D., Knox, N. C., Peterson, C. L. $\&$ Reimer, A. R. Highlighting clinical metagenomics for enhanced diagnostic decision-making: a step towards wider implementation. Comput. Struct. Biotechnol. J. 16, 108-120 (2018)

65. Swirski, F. K. \& Nahrendorf, M. Cardioimmunology: the immune system in cardiac homeostasis and disease. Nat. Rev. Immunol. 18, 733-744 (2018).

66. Pollack, A., Kontorovich, A. R., Fuster, V. \& Dec, G. W. Viral myocarditis-diagnosis, treatment options, and current controversies. Nat. Rev. Cardiol. 12, 670-680 (2015).

67. Alexopoulou, L., Holt, A. C., Medzhitov, R. \& Flavell, R. A. Recognition of double-stranded RNA and activation of NF-kappaB by Toll-like receptor 3. Nature 413, 732-738 (2001).

68. Tschope, C. et al. NOD2 (nucleotide-binding oligomerization domain 2) is a major pathogenic mediator of coxsackievirus B3-induced myocarditis. Circ. Heart Fail. 10, e003870 (2017).

69. Miteva, K. et al. Mesenchymal stromal cells inhibit NLRP3 inflammasome activation in a model of coxsackievirus B3-induced inflammatory cardiomyopathy. Sci. Rep. 8, 2820 (2018).

70. Muller, I. et al. Serum alarmin S100A8/S100A9 levels and its potential role as biomarker in myocarditis. ESC Heart Fail. 7, 1442-1451 (2020).

71. Heymans, S., Eriksson, U., Lehtonen, J. \& Cooper, L. T. Jr. The quest for new approaches in myocarditis and inflammatory cardiomyopathy. J. Am . Coll. Cardiol. 68, 2348-2364 (2016).

72. Huang, C. H., Vallejo, J. G., Kollias, G. \& Mann, D. L. Role of the innate immune system in acute viral myocarditis. Basic. Res. Cardiol. 104, 228-237 (2009).

73. Libby, P., Nahrendorf, M. ¿ Swirski, F. K. Leukocytes link local and systemic inflammation in ischemic cardiovascular disease: an expanded "cardiovascular continuum". J. Am. Coll. Cardiol. 67, 1091-1103 (2016).

74. Leuschner, F. et al. Rapid monocyte kinetics in acute myocardial infarction are sustained by extramedullary monocytopoiesis. J. Exp. Med. 209, 123-137 (2012) 
75. Swirski, F. K. et al. Identification of splenic reservoir monocytes and their deployment to inflammatory sites. Science 325, 612-616 (2009).

76. Ismahil, M. A. et al. Remodeling of the mononuclear phagocyte network underlies chronic inflammation and disease progression in heart failure: critical importance of the cardiosplenic axis. Circ. Res. 114 266-282 (2014)

77. Leuschner, F. et al. Silencing of CCR2 in myocarditis. Eur. Heart J. 36, 1478-1488 (2015)

78. Miteva, K. et al. Mesenchymal stromal cells modulate monocytes trafficking in coxsackievirus B3-induced myocarditis. Stem Cell Transl Med. 6, 1249-1261 (2017).

79. Cooper, L. T. Jr. \& Fairweather, D. Nano-scale treatment for a macro-scale disease: nanoparticle-delivered siRNA silences CCR2 and treats myocarditis. Eur. Heart J. 36 1434-1436 (2015)

80. Pappritz, K. et al. Immunomodulation by adoptive regulatory T-cell transfer improves Coxsackievirus B3-induced myocarditis. FASEB J. 32, 6066-6078 (2018).

81. Muller, I. et al. CX3CR1 knockout aggravates Coxsackievirus B3-induced myocarditis. PLOS ONE 12 e0182643 (2017).

82. Klingel, K. et al. Pathogenesis of murine enterovirus myocarditis: virus dissemination and immune cell targets. J. Virol. 70, 8888-8895 (1996).

83. Hofmann, P., Schmidtke, M., Stelzner, A. \& Gemsa, D. Suppression of proinflammatory cytokines and induction of IL-10 in human monocytes after Coxsackievirus B3 infection. J. Med. Virol. 64, 487-498 (2001)

84. Kandolf, R. et al. Mechanisms and consequences of enterovirus persistence in cardiac myocytes and cells of the immune system. Virus Res. 62, 149-158 (1999).

85. Savvatis, K. et al. Mesenchymal stromal cells but not cardiac fibroblasts exert beneficial systemic immunomodulatory effects in experimental myocarditis. PLoS ONE 7, e41047 (2012).

86. Fairweather, D et al. Mast cells and innate cytokines are associated with susceptibility to autoimmune heart disease following coxsackievirus B3 infection. Autoimmunity 37, 131-145 (2004).

87. Klingel, K. et al. The activating receptor NKG2D of natural killer cells promotes resistance against enterovirus-mediated inflammatory cardiomyopathy J. Pathol. 234, 164-177 (2014).

88. Yuan, J. et al. CXCL10 inhibits viral replication through recruitment of natural killer cells in coxsackievirus B3-induced myocarditis. Circ. Res. 104, 628-638 (2009).

89. Clemente-Casares, X. et al. A CD103(+) conventional dendritic cell surveillance system prevents development of overt heart failure during subclinical viral myocarditis. Immunity 47, 974-989 e978 (2017).

90. Eriksson, U. et al. Dendritic cell-induced autoimmune heart failure requires cooperation between adaptive and innate immunity. Nat. Med. 9, 1484-1490 (2003).

91. Xu, D. et al. Gr-1+ cells other than Ly6G+ neutrophils limit virus replication and promote myocardial inflammation and fibrosis following coxsackievirus B3 infection of mice. Front. Cell Infect. Microbiol. 8, 157 (2018).

92. Rivadeneyra, L. et al. Role of neutrophils in CVB3 infection and viral myocarditis. J. Mol. Cell Cardiol. 125, 149-161 (2018)

93. Weckbach, L. T. et al. Midkine drives cardiac inflammation by promoting neutrophil trafficking and NETosis in myocarditis. J. Exp. Med. 216, 350-368 (2019).

94. Afanasyeva, M. et al. Quantitative analysis of myocardial inflammation by flow cytometry in murine autoimmune myocarditis: correlation with cardiac function. Am. J. Pathol. 164, 807-815 (2004)

95. Muller, I. et al. Pathogenic role of the damageassociated molecular patterns S100A8 and S100A9 in coxsackievirus B3-induced myocarditis. Circ. Heart Fail. 10, e004125 (2017)

96. Tahto, E., Jadric, R., Pojskic, L. \& Kicic, E. Neutrophilto-lymphocyte ratio and its relation with markers of inflammation and myocardial necrosis in patients with acute coronary syndrome. Med. Arch. 71, 312-315 (2017).

97. Nahrendorf, M. \& Swirski, F. K. Monocyte and macrophage heterogeneity in the heart. Circ. Res. 112, 1624-1633 (2013).

98. Yang, J., Zhang, L., Yu, C., Yang, X. F. \& Wang, H. Monocyte and macrophage differentiation: circulation inflammatory monocyte as biomarker for inflammatory diseases. Biomark Res. 2, 1 (2014).
99. Pappritz, K. et al. Cardiac (myo)fibroblasts modulate the migration of monocyte subsets. Sci. Rep. 8, 5575 (2018).

100. Hou, X. et al. The cardiac microenvironment instructs divergent monocyte fates and functions in myocarditis. Cell Rep. 28, 172-189 (2019)

101. Liu, P. et al. The tyrosine kinase p56lck is essential in coxsackievirus B3-mediated heart disease. Nat. Med. 6, 429-434 (2000).

102. Baldeviano, G. C. et al. Interleukin-17A is dispensable for myocarditis but essential for the progression to dilated cardiomyopathy. Circ. Res. 106, 1646-1655 (2010).

103. Shi, Y. et al. Regulatory T cells protect mice against coxsackievirus-induced myocarditis through the transforming growth factor $\beta$-coxsackie-adenovirus receptor pathway. Circulation 121, 2624-2634 (2010).

104. Anzai, A. et al. Self-reactive CD4(+) IL-3(+) T cells amplify autoimmune inflammation in myocarditis by inciting monocyte chemotaxis. J. Exp. Med. 216, 369-383 (2019).

105. Opavsky, M. A. et al. Susceptibility to myocarditis is dependent on the response of alphabeta T lymphocytes to coxsackieviral infection. Circ. Res. 85, 551-558 (1999).

106. Klingel, K., Schnorr, J. J., Sauter, M., Szalay, G. \& Kandolf, R. $\beta 2$-Microglobulin-associated regulation of interferon- $\gamma$ and virus-specific immunoglobulin $G$ confer resistance against the development of chronic coxsackievirus myocarditis. Am. J. Pathol. 162 1709-1720 (2003).

107. Rangachari, M. et al. T-bet negatively regulates autoimmune myocarditis by suppressing local production of interleukin 17. J. Exp. Med. 203 2009-2019 (2006).

108. Myers, J. M. et al. Cardiac myosin-Th17 responses promote heart failure in human myocarditis. JCI Insight 1, e85851 (2016).

109. Ahern, P. P. et al. Interleukin-23 drives intestinal inflammation through direct activity on T cells. Immunity 33, 279-288 (2010).

110. Wu, L. et al. Pathogenic IL-23 signaling is required to initiate GM-CSF-driven autoimmune myocarditis in mice. Eur. J. Immunol. 46, 582-592 (2016).

111. Kaya, Z., Leib, C. $\&$ Katus, H. A. Autoantibodies in heart failure and cardiac dysfunction. Circ. Res. 110 145-158 (2012)

112. Weber, M. S. et al. B-cell activation influences T-cell polarization and outcome of anti-CD20 B-cell depletion in central nervous system autoimmunity. Ann. Neurol. 68, 369-383 (2010).

113. Zouggari, Y. et al. B lymphocytes trigger monocyte mobilization and impair heart function after acute myocardial infarction. Nat. Med. 19, 1273-1280 (2013).

114. Tschope, C. et al. Targeting CD20+ B-lymphocytes in inflammatory dilated cardiomyopathy with rituximab improves clinical course: a case series. Eur. Heart J. Case Rep. 3, ytz131 (2019).

115. Diny, N. L. et al. Eosinophil-derived IL-4 drives progression of myocarditis to inflammatory dilated cardiomyopathy. J. Exp. Med. 214, 943-957 (2017).

116. Tai, P. C. et al. Deposits of eosinophil granule proteins in cardiac tissues of patients with eosinophilic endomyocardial disease. Lancet 1 , 643-647 (1987).

117. Thambidorai, S. K. Korlakunta, H. L., Arouni, A. J., Hunter, W. J. \& Holmberg, M. J. Acute eosinophilic myocarditis mimicking myocardial infarction. Tex. Heart Inst. J. 36, 355-357 (2009)

118. Song, T., Jones, D. M. \& Homsi, Y. Therapeutic effect of anti-IL-5 on eosinophilic myocarditis with large pericardial effusion. BMJ Case Rep. 2017 bcr2016218992 (2017)

119. Mahon, N. G. et al. Immunohistologic evidence of myocardial disease in apparently healthy relative of patients with dilated cardiomyopathy. J. Am. Coll. Cardiol. 39, 455-462 (2002).

120. Caforio, A. L. et al. Evidence from family studies for autoimmunity in dilated cardiomyopathy. Lancet 344 773-777 (1994)

121. Caforio, A. L. et al. Prospective familial assessment in dilated cardiomyopathy: cardiac autoantibodies predict disease development in asymptomatic relatives. Circulation 115, 76-83 (2007)

122. Mestroni, L. et al. Familial dilated cardiomyopathy: evidence for genetic and phenotypic heterogeneity. Heart Muscle Disease Study Group. J. Am. Coll. Cardiol. 34, 181-190 (1999).

123. Neu, N. et al. Cardiac myosin induces myocarditis in genetically predisposed mice. J. Immunol. 139 , 3630-3636 (1987).
124. Smith, S. C. \& Allen, P. M. Myosin-induced acute myocarditis is a T cell-mediated disease. J. Immunol. 147, 2141-2147 (1991)

125. Li, Y., Heuser, J. S., Cunningham, L. C., Kosanke, S. D. \& Cunningham, M. W. Mimicry and antibody-mediated cell signaling in autoimmune myocarditis. J. Immunol. 177, 8234-8240 (2006).

126. Frustaci, A. et al. Immunosuppressive therapy for activ lymphocytic myocarditis: virological and immunologic profile of responders versus nonresponders. Circulation 107, 857-863 (2003).

127. Frustaci, A., Russo, M. A \& Chimenti, C. Randomized study on the efficacy of immunosuppressive therapy in patients with virus-negative inflammatory cardiomyopathy: the TIMIC study. Eur. Heart J. 30, 1995-2002 (2009).

128. Escher, $\mathrm{F}$, et al. Long-term outcome of patients with virus-negative chronic myocarditis or inflammatory cardiomyopathy after immunosuppressive therapy. Clin. Res. Cardiol. 105, 1011-1020 (2016).

129. Caforio, A. L. et al. Novel organ-specific circulating cardiac autoantibodies in dilated cardiomyopathy. J. Am. Coll. Cardiol. 15, 1527-1534 (1990).

130. Caforio, A. L. et al. A prospective study of biopsyproven myocarditis: prognostic relevance of clinical and aetiopathogenetic features at diagnosis. Eur. Heart J. 28, 1326-1333 (2007).

131. Caforio, A. L. et al. Identification of alpha- and beta-cardiac myosin heavy chain isoforms as major autoantigens in dilated cardiomyopathy. Circulation 85, 1734-1742 (1992).

132. Schulze, K., Becker, B. F. \& Schultheiss, H. P. Antibodies to the ADP/ATP carrier, an autoantigen in myocarditis and dilated cardiomyopathy, penetrate into myocardia cells and disturb energy metabolism in vivo. Circ. Res. 64, 179-192 (1989)

133. Caforio, A. L. et al. Passive transfer of affinity-purified anti-heart autoantibodies (AHA) from sera of patients with myocarditis induces experimental myocarditis in mice. Int. J. Cardiol. 179, 166-177 (2015).

134. Zwacka, R. M. et al. Redox gene therapy for ischemia/ reperfusion injury of the liver reduces AP 1 and NF-kB activation. Nat. Med. 4, 698-704 (1998).

135. Jahns, R. et al. Direct evidence for a $\beta 1$-adrenergic receptor-directed autoimmune attack as a cause of idiopathic dilated cardiomyopathy. J. Clin. Invest. 113, 1419-1429 (2004)

136. Nishimura, $\mathrm{H}$. et al. Autoimmune dilated cardiomyopathy in PD-1 receptor-deficient mice. Science 291, 319-322 (2001).

137. Meder, B. et al. A genome-wide association study identifies $6 \mathrm{p} 21$ as novel risk locus for dilated cardiomyopathy. Eur. Heart J. 35, 1069-1077 (2014).

138. Arbustini, E. et al. The MOGE(S) classification for a phenotype-genotype nomenclature of cardiomyopathy: endorsed by the World Heart Federation. J. Am. Coll. Cardiol. 62, 2046-2072 (2013).

139. Hazebroek, M. R. et al. Prognostic relevance of geneenvironment interactions in patients with dilated cardiomyopathy: applying the MOGE(S) classification. J. Am. Coll. Cardiol. 66, 1313-1323 (2015).

140. Pinto, Y. M. et al. Proposal for a revised definition of dilated cardiomyopathy, hypokinetic non-dilated cardiomyopathy, and its implications for clinical practice: a position statement of the ESC working group on myocardial and pericardial diseases. Eur. Heart J. 37, 1850-1858 (2016)

141. Gil-Cruz, C. et al. Microbiota-derived peptide mimics drive lethal inflammatory cardiomyopathy. Science 366, 881-886 (2019).

142. Blyszczuk, P. Myocarditis in humans and in experimenta animal models. Front. Cardiovasc. Med. 6, 64 (2019).

143. Grodums, E. I. \& Dempster, G. Myocarditis in experimental coxsackie B-3 infection. Can. J. Microbiol. 5, 605-615 (1959).

144. Klingel, K. et al. Ongoing enterovirus-induced myocarditis is associated with persistent heart muscle infection: quantitative analysis of virus replication, tissue damage, and inflammation. Proc. Natl Acad. Sci. USA 89, 314-318 (1992).

145. Tracy, S. et al. Group B coxsackievirus myocarditis and pancreatitis: connection between viral virulence phenotypes in mice. J. Med. Virol. 62, 70-81 (2000).

146. Schmidt-Lucke, C. et al. Interferon beta modulates endothelial damage in patients with cardiac persistence of human parvovirus b19 infection. J. Infect. Dis. 201, 936-945 (2010)

147. Tschope, C. et al. High prevalence of cardiac parvovirus B19 infection in patients with isolated left ventricular diastolic dysfunction. Circulation 111, 879-886 (2005). 
148. Bachelier, K. et al. Parvovirus B19-induced vascular damage in the heart is associated with elevated circulating endothelial microparticles. PLOS ONE 12 e0176311 (2017)

149. Huber, S. A. \& Lodge, P. A. Coxsackievirus B-3 myocarditis. Identification of different pathogenic mechanisms in DBA/2 and Balb/c mice. Am. J. Pathol. 122, 284-291 (1986).

150. Bruno, K. A. et al. BPA alters estrogen receptor expression in the heart after viral infection activating cardiac mast cells and $\mathrm{T}$ cells leading to perimyocarditis and fibrosis. Front. Endocrinol. 10, 598 (2019).

151. Bucher, C. H. et al. Experience in the adaptive immunity impacts bone homeostasis, remodeling, and healing. Front. Immunol. 10, 797 (2019)

152. Andreadou, I. et al. Immune cells as targets for cardioprotection: new players and novel therapeutic opportunities. Cardiovasc. Res. 115, 1117-1130 (2019).

153. Sharma, A. et al. Human induced pluripotent stem cell-derived cardiomyocytes as an in vitro model for coxsackievirus B3-induced myocarditis and antiviral drug screening platform. Circ. Res. 115, 556-566 (2014).

154. Van Linthout, S., Tschope, C. \& Schultheiss, H. P. Lack in treatment options for virus-induced inflammatory cardiomyopathy: can iPS-derived cardiomyocytes close the gap? Circ. Res. 115, 540-541 (2014).

155. Corrado, D., Basso, C. ¿ Thiene, G. Sudden cardiac death in young people with apparently normal heart Cardiovasc. Res. 50, 399-408 (2001).

156. Aquaro, G. D. et al. Cardiac MR with late gadolinium enhancement in acute myocarditis with preserved systolic function: ITAMY study. J. Am. Coll. Cardiol. 70 1977-1987 (2017)

157. Kasner, M. et al. Multimodality imaging approach in the diagnosis of chronic myocarditis with preserved left ventricular ejection fraction (MCpEF): the role of 2D speckle-tracking echocardiography. Int. J. Cardiol. 243, 374-378 (2017).

158. Ammirati, E. et al. Acute and fulminant myocarditis: a pragmatic clinical approach to diagnosis and treatment. Curr. Cardiol. Rep. 20, 114 (2018).

159. Tschope, C., Cooper, L. T., Torre-Amione, G. \& Van Linthout, S. Management of myocarditis-related cardiomyopathy in adults. Circ. Res. 124, 1568-1583 (2019)

160. Merlo, M. et al. Persistent left ventricular dysfunction after acute lymphocytic myocarditis: frequency and predictors. PLOS ONE 14, e0214616 (2019).

161. McMurray, J. J. et al. ESC Guidelines for the diagnosis and treatment of acute and chronic heart failure 2012: The Task Force for the Diagnosis and Treatment of Acute and Chronic Heart Failure 2012 of the European Society of Cardiology. Developed in collaboration with the Heart Failure Association (HFA) of the ESC. Eur. Heart J. 33, 1787-1847 (2012).

162. Ferreira, V. M. et al. Cardiovascular magnetic resonance in nonischemic myocardial inflammation: expert recommendations. J. Am. Coll. Cardiol. 72, 3158-3176 (2018).

163. Luetkens, J. A. et al. Comparison of original and 2018 Lake Louise criteria for diagnosis of acute myocarditis: results of a validation cohort. Radiol. Cardiothorac. Imaging https://doi.org/10.1148/ryct.2019190010 (2019).

164. Thavendiranathan, P. et al. Improved detection of myocardial involvement in acute inflammatory cardiomyopathies using T2 mapping. Circ. Cardiovasc. Imaging 5, 102-110 (2012).

165. Messroghli, D. R. et al. Clinical recommendations for cardiovascular magnetic resonance mapping of $\mathrm{T} 1, \mathrm{~T} 2, \mathrm{~T} 2{ }^{*}$ and extracellular volume: A consensus statement by the Society for Cardiovascular Magnetic Resonance (SCMR) endorsed by the European Association for Cardiovascular Imaging (EACVI) J. Cardiovasc. Magn. Reson. 19, 75 (2017)

166. Bohnen, S. et al. Performance of T1 and T2 mapping cardiovascular magnetic resonance to detect active myocarditis in patients with recent-onset heart failure. Circ. Cardiovasc. Imaging 8, e003073 (2015).

167. Radunski, U. K. et al. T1 and T2 mapping cardiovascular magnetic resonance imaging techniques reveal unapparent myocardial injury in patients with myocarditis. Clin. Res. Cardiol. 106, 10-17 (2017).

168. Lurz, P. et al. Comprehensive cardiac magnetic resonance imaging in patients with suspected myocarditis: the MyoRacer-trial. J. Am. Coll. Cardiol. 67, 1800-1811 (2016)

169. Puntmann, V. O., Zeiher, A. M. \& Nagel, E. T1 and T2 mapping in myocarditis: seeing beyond the horizon of
Lake Louise criteria and histopathology. Expert Rev. Cardiovasc. Ther. 16, 319-330 (2018).

170. Francone, M. et al. CMR sensitivity varies with clinical presentation and extent of cell necrosis in biopsyproven acute myocarditis. JACC Cardiovasc. Imaging 7, 254-263 (2014).

171. Tanacli, R. et al. Range variability in CMR feature tracking multilayer strain across different stages of heart failure. Sci. Rep. 9, 16478 (2019).

172. Escher, F. et al. Development of diastolic heart failure in a 6-year follow-up study in patients after acute myocarditis. Heart 97, 709-714 (2011).

173. Bohnen, S. et al. Tissue characterization by $\mathrm{T} 1$ and T2 mapping cardiovascular magnetic resonance imaging to monitor myocardial inflammation in healing myocarditis. Eur. Heart J. Cardiovasc. Imaging 18, 744-751 (2017)

174. Heidecker, B. et al. Systematic use of cardiac magnetic resonance imaging in MINOCA led to a five-fold increase in the detection rate of myocarditis: a retrospective study. Swiss Med. Wkly. 149, w20098 (2019).

175. Patriki, D. et al. Approximation of the incidence of myocarditis by systematic screening with cardiac magnetic resonance imaging. JACC Heart Fail. 6 , 573-579 (2018)

176. Jessup, M. \& Lindenfeld, J. Light at the end of the myocarditis tunnel. JACC Heart Fail. 6, 580-582 (2018).

177. Schneider, J. E. \& Stojanovic, I. Economic evaluation of cardiac magnetic resonance with fast-SENC in the diagnosis and management of early heart failure. Health Econ. Rev. 9, 13 (2019).

178. Ge, Y. et al. Cost-effectiveness analysis of stress cardiovascular magnetic resonance imaging for stable chest pain syndromes. JACC Cardiovasc. Imaging 13, 1505-1517 (2020).

179. Petrov, G., Kelle, S., Fleck, E. \& Wellnhofer, E. Incremental cost-effectiveness of dobutamine stress cardiac magnetic resonance imaging in patients at intermediate risk for coronary artery disease. Clin Res Cardiol 104, 401-409 (2015).

180. Cooper, L. T. et al. The role of endomyocardial biopsy in the management of cardiovascular disease: a scientific statement from the American Heart Association, the American College of Cardiology, and the European Society of Cardiology. Circulation 116, 2216-2233 (2007).

181. Backhaus, S. J. et al. Real-time cardiovascular magnetic resonance $\mathrm{T} 1$ and extracellular volume fraction mapping for tissue characterisation in aortic stenosis. J. Cardiovasc. Magn. Reson. 22, 46 (2020).

182. Zhang, S. et al. Real-time magnetic resonance imaging of cardiac function and flow-recent progress. Quant. Imaging Med. Surg. 4, 313-329 (2014).

183. Lurz, P. et al. Diagnostic performance of CMR imaging compared with EMB in patients with suspected myocarditis. JACC Cardiovasc. Imaging 5, 513-524 (2012).

184. Grani, C. et al. Prognostic value of cardiac magnetic resonance tissue characterization in risk stratifying patients with suspected myocarditis. J. Am. Coll. Cardiol. 70, 1964-1976 (2017)

185. Schelbert, E. B. et al. Myocardial fibrosis quantified by extracellular volume is associated with subsequent hospitalization for heart failure, death, or both across the spectrum of ejection fraction and heart failure stage. J. Am. Heart Assoc. 4, e002613 (2015).

186. Mewton, N., Liu, C. Y., Croisille, P., Bluemke, D \& Lima, J. A. Assessment of myocardial fibrosis with cardiovascular magnetic resonance. J. Am. Coll. Cardiol. 57, 891-903 (2011).

187. Berg, J. et al. Cardiac magnetic resonance imaging in myocarditis reveals persistent disease activity despite normalization of cardiac enzymes and inflammatory parameters at 3-month follow-up. Circ. Heart Fail. 10 e004262 (2017).

188. Murtagh, G. et al. Prognosis of myocardial damage in sarcoidosis patients with preserved left ventricular ejection fraction: risk stratification using cardiovascular magnetic resonance. Circ. Cardiovasc. Imaging 9, e003738 (2016)

189. Nensa, F. et al. Hybrid cardiac imaging using PET/MRI a joint position statement by the European Society of Cardiovascular Radiology (ESCR) and the European Association of Nuclear Medicine (EANM). Eur. Radiol. 28, 4086-4101 (2018)

190. Lapinskas, T. et al. The Intraventricular hemodynamic forces estimated using routine CMR cine images: a new marker of the failing heart. JACC Cardiovasc. Imaging 12, 377-379 (2019).
191. Frey, N., Meder, B. \& Katus, H. A. Left ventricular biopsy in the diagnosis of myocardial diseases. Circulation 137, 993-995 (2018).

192. Nakayama, T., Murai, S. \& Ohte, N. Dilated cardiomyopathy with eosinophilic granulomatosis with polyangiitis in which active myocardial inflammation was only detected by endomyocardial biopsy. Intern. Med. 57, 2675-2679 (2018).

193. Cooper, L. T. et al. The role of endomyocardial biopsy in the management of cardiovascular disease: a scientific statement from the American Heart Association, the American College of Cardiology, and the European Society of Cardiology Endorsed by the Heart Failure Society of America and the Heart Failure Association of the European Society of Cardiology. Eur. Heart J. 28, 3076-3093 (2007).

194. Leone, O. et al. 2011 consensus statement on endomyocardial biopsy from the Association for European Cardiovascular Pathology and the Society for Cardiovascular Pathology. Cardiovasc. Pathol. 21, 245-274 (2012).

195. Katzmann J L. et al. Meta-analysis on the immunohistological detection of inflammatory cardiomyopathy in endomyocardial biopsies. Heart Fail. Rev. 25, 277-294 (2019).

196. Baughman, K. L. Diagnosis of myocarditis: death of Dallas criteria Circulation 113,593-595 (2006).

197. Andreoletti, L., Leveque, N., Boulagnon, C., Brasselet, C. $\&$ Fornes, P. Viral causes of human myocarditis. Arch. Cardiovasc. Dis. 102, 559-568 (2009).

198. Badorff, C. \& Knowlton, K. U. Dystrophin disruption in enterovirus-induced myocarditis and dilated cardiomyopathy: from bench to bedside. Med. Microbiol. Immunol. 193, 121-126 (2004).

199. Spieker, M. et al. Abnormal T2 mapping cardiovascular magnetic resonance correlates with adverse clinical outcome in patients with suspected acute myocarditis. J. Cardiovasc. Magn. Reson. 19, 38 (2017).

200. Unterberg-Buchwald, C. et al. Targeted endomyocardial biopsy guided by real-time cardiovascular magnetic resonance. J. Cardiovasc. Magn. Reson. 19, 45 (2017).

201. Casella, M. et al. Feasibility of combined unipolar and bipolar voltage maps to improve sensitivity of endomyocardial biopsy. Circ. Arrhythm. Electrophysiol. 8, 625-632 (2015).

202. Liang, J. J. et al. Electrogram guidance: a method to increase the precision and diagnostic yield of endomyocardial biopsy for suspected cardiac sarcoidosis and myocarditis. JACC Heart Fail. 2 466-473 (2014).

203. Konecny, T. et al. Endomyocardial biopsy-integrating electrode at the bioptome tip. Ther. Adv. Cardiovasc. Dis. 9, 66-69 (2015).

204. Vaidya, V. R. et al. The efficacy and safety of electroanatomic mapping-guided endomyocardial biopsy: a systematic review. J. Interv. Card. Electrophysiol. 53, 63-71 (2018).

205. Omote, K. et al. (18)F-FDG uptake of the right ventricle is an important predictor of histopathologic diagnosis by endomyocardial biopsy in patients with cardiac sarcoidosis. J. Nucl. Cardiol. https://doi.org/ 10.1007/s12350-018-01541-7 (2019).

206. Van Linthout, S. \& Tschope, C. Viral myocarditis: a prime example for endomyocardial biopsy-guided diagnosis and therapy. Curr. Opin. Cardiol. 33 325-333 (2018)

207. Lassner, D. et al. Improved diagnosis of idiopathic giant cell myocarditis and cardiac sarcoidosis by myocardial gene expression profiling. Eur. Heart J. 35 2186-2195 (2014).

208. Hammer, E., Darm, K. \& Volker, U. Characterization of the human myocardial proteome in dilated cardiomyopathy by label-free quantitative shotgun proteomics of heart biopsies. Methods Mol. Biol. 1005, 67-76 (2013)

209. Van Linthout, S. \& Tschope, C. Lost in markers? Time for phenomics and phenomapping in dilated cardiomyopathy. Eur. J. Heart Fail. 19, 499-501 (2017).

210. Soler-Botija, C., Galvez-Monton, C. \& Bayes-Genis, A. Epigenetic biomarkers in cardiovascular diseases. Front. Genet. 10, 950 (2019).

211. Halliday, B. P., Cleland, J. G. F., Goldberger, J. J. $\&$ Prasad, S. K. Personalizing risk stratification for sudden death in dilated cardiomyopathy: the past present, and future. Circulation 136, 215-231 (2017).

212. Takeuchi, S. et al. Identification of potential pathogenic viruses in patients with acute myocarditis using nextgeneration sequencing. J. Med. Virol. 90, 1814-182 (2018). 
213. Kannan, S. et al. Large particle fluorescence-activated cell sorting enables high-quality single-cell RNA sequencing and functional analysis of adult cardiomyocytes. Circ. Res. 125, 567-569 (2019).

214. Martini, E. et al. Single cell sequencing of mouse heart immune infiltrate in pressure overload-driven heart failure reveals extent of immune activation. Circulation 140, 2089-2107 (2019)

215. Shah, S. J. et al. Phenomapping for novel classification of heart failure with preserved ejection fraction. Circulation 131, 269-279 (2015)

216. Reichl, K., Kreykes, S. E., Martin, C. M. \& Shenoy, C. Desmoplakin variant-associated arrhythmogenic cardiomyopathy presenting as acute myocarditis. Circ. Genom. Precis. Med. 11, e002373 (2018).

217. Calabrese, F., Basso, C., Carturan, E., Valente, M. $\&$ Thiene, G. Arrhythmogenic right ventricular cardiomyopathy/dysplasia: is there a role for viruses? Cardiovasc. Pathol. 15, 11-17 (2006)

218. Lopez-Ayala, J. M. et al. Genetics of myocarditis in arrhythmogenic right ventricular dysplasia. Heart Rhythm. 12, 766-773 (2015).

219. Protonotarios, A. et al. Prevalence of (18)Ffluorodeoxyglucose positron emission tomography abnormalities in patients with arrhythmogenic right ventricular cardiomyopathy. Int. J. Cardiol. 284 99-104 (2019).

220. Hata, Y. et al. Minimal inflammatory foci of unknown etiology may be a tentative sign of early stage inherited cardiomyopathy. Mod. Pathol. 32, 1281-1290 (2019)

221. Belkaya S et al. Autosomal recessive cardiomyopath presenting as acute myocarditis. J. Am. Coll. Cardiol. 69, 1653-1665 (2017)

222. Small, E. M. \& Olson, E. N. Pervasive roles of microRNAs in cardiovascular biology. Nature 469 336-342 (2011).

223. Corsten, M. F. et al. MicroRNA profiling identifies microRNA-155 as an adverse mediator of cardiac injury and dysfunction during acute viral myocarditis Circ. Res. 111, 415-425 (2012).

224. Kuehl, U. et al. Differential cardiac microRNA expression predicts the clinical course in human enterovirus cardiomyopathy. Circ. Heart Fail. 8 605-618 (2015).

225. Navarro, I. C. et al. MicroRNA transcriptome profiling in heart of Trypanosoma cruzi-infected mice: parasitological and cardiological outcomes. PLoS Negl. Trop. Dis. 9, e0003828 (2015)

226. Corsten, M. F. et al. Circulating microRNA-208b and microRNA-499 reflect myocardial damage in cardiovascular disease. Circ. Cardiovasc. Genet. 3 499-506 (2010)

227. Goldberg, L. et al. Circulating microRNAs: a potentia biomarker for cardiac damage, inflammatory response, and left ventricular function recovery in pediatric viral myocarditis. J. Cardiovasc. Trans/ Res. 11, 319-328 (2018)

228. Devaux, Y. et al. Use of circulating microRNAs to diagnose acute myocardial infarction. Clin. Chem. 58, 559-567 (2012)

229. Heidecker, B. et al. Transcriptomic biomarkers for the accurate diagnosis of myocarditis. Circulation 123 1174-1184 (2011).

230. Chen, P. et al. Susceptibility to autoimmune myocarditis is associated with intrinsic differences in CD4(+) T cells. Clin. Exp. Immunol. 169, 79-88 (2012).

231. Li, J. et al. The Treg/Th1 7 imbalance in patients with idiopathic dilated cardiomyopathy. Scand. J. Immunol. 71, 298-303 (2010).

232. Benincasa, G., Mansueto, G. \& Napoli, C. Fluid-based assays and precision medicine of cardiovascular diseases: the 'hope' for Pandora's box? J. Clin. Pathol. 72, 785-799 (2019).

233. Kennel, P. J. et al. Serum exosomal protein profiling for the non-invasive detection of cardiac allograft rejection. J. Heart Lung Transpl. 37, 409-417 (2018).

234. Ponikowski, P. et al. 2016 ESC Guidelines for the diagnosis and treatment of acute and chronic heart failure: The Task Force for the diagnosis and treatment of acute and chronic heart failure of the European Society of Cardiology (ESC). Developed with the special contribution of the Heart Failure Association (HFA) of the ESC. Eur. J. Heart Fail. 18, 891-975 (2016).

235. Peretto, G. et al. Ventricular arrhythmias in myocarditis: characterization and relationships with myocardial inflammation. J. Am. Coll. Cardiol. 75, 1046-1057 (2020).

236. Baksi, A. J., Kanaganayagam, G. S. \& Prasad, S. K. Arrhythmias in viral myocarditis and pericarditis. Card. Electrophysiol. Clin. 7, 269-281 (2015).

237. Cooper, L. T. Jr., Berry, G. J. \& Shabetai, R. Idiopathic giant-cell myocarditis-natural history and treatment.
Multicenter Giant Cell Myocarditis Study Group investigators. N. Engl. J. Med. 336, 1860-1866 (1997).

238. Birnie, D. H. et al. HRS expert consensus statement on the diagnosis and management of arrhythmias associated with cardiac sarcoidosis. Heart Rhythm. 11, 1305-1323 (2014).

239. Imazio, M. \& Trinchero, R. Myopericarditis: etiology, management, and prognosis. Int. J. Cardiol. 127, $17-26$ (2008).

240. Adegbala 0 et al Predictors, burden and the impact of arrhythmia on patients admitted for acute myocarditis. Am. J. Cardiol. 123, 139-144 (2019).

241. Maron, B. J. et al. Eligibility and disqualification recommendations for competitive athletes with cardiovascular abnormalities: Task Force 3: Hypertrophic cardiomyopathy, arrhythmogenic right ventricular cardiomyopathy and other cardiomyopathies, and myocarditis: a scientific statement from the American Heart Association and American College of Cardiology. J. Am. Coll. Cardiol. 66, 2362-2371 (2015)

242. Zorzi, A. et al. Nonischemic left ventricular scar as a substrate of life-threatening ventricular arrhythmias and sudden cardiac death in competitive athletes. Circ. Arrhythm. Electrophysiol. 9, e004229 (2016)

243. Steinke, K. et al. Coxsackievirus B3 modulates cardiac ion channels. FASEB J. 27, 4108-4121 (2013).

244. Priori, S. G. et al. 2015 ESC Guidelines for the management of patients with ventricular arrhythmias and the prevention of sudden cardiac death: The Task Force for the Management of Patients with Ventricular Arrhythmias and the Prevention of Sudden Cardiac Death of the European Society of Cardiology (ESC). Endorsed by: Association for European Paediatric and Congenital Cardiology (AEPC). Europace 17 1601-1687 (2015).

245. Sheppard, R. et al. Implantable cardiac defibrillators and sudden death in recent onset nonischemic cardiomyopathy: results from IMAC2. J. Card. Fail. 18, 675-681 (2012)

246. Chung, M. K. The role of the wearable cardioverter defibrillator in clinical practice. Cardiol. Clin. 32, 253-270 (2014)

247. Halle, M. et al. Myocarditis in athletes: a clinical perspective Eur J Prev Cardiol https://doi org 10.1177/2047487320909670 (2020).

248. Wojnicz, R. et al. Randomized, placebo-controlled study for immunosuppressive treatment of inflammatory dilated cardiomyopathy: two-year follow-up results. Circulation 104, 39-45 (2001).

249. Merken, J. et al. Immunosuppressive therapy improves both short- and long-term prognosis in patients with virus-negative nonfulminant inflammatory cardiomyopathy. Circ. Heart Fail. 11, e004228 (2018).

250. Kleinert S. Weintraub, R. G Wilkinson, J L $\&$ Chow, C. W. Myocarditis in children with dilated cardiomyopathy: incidence and outcome after dual therapy immunosuppression. J. Heart Lung Transpl. 16, 1248-1254 (1997)

251. De Luca, G. et al. Efficacy and safety of mycophenolate mofetil in patients with virus-negative lymphocytic myocarditis: a prospective cohort study. J. Autoimmun 106, 102330 (2020)

252. Felix, S. B. et al. Hemodynamic effects of immunoadsorption and subsequent immunoglobulin substitution in dilated cardiomyopathy: three-month results from a randomized study. J. Am. Coll. Cardiol. 35, 1590-1598 (2000)

253. Trimpert, C. et al. Immunoadsorption in dilated cardiomyopathy: long-term reduction of cardiodepressant antibodies. Eur. J. Clin. Invest. 40, 685-691 (2010).

254. Dandel, M. et al. Long-term benefits of immunoadsorption in $\beta(1)$-adrenoceptor autoantibody-positive transplant candidates with dilated cardiomyopathy. Eur. J. Heart Fail. 14, 1374-1388 (2012).

255. Kronbichler, A., Brezina, B., Quintana, L. F. \& Jayne, D. R. Efficacy of plasma exchange and immunoadsorption in systemic lupus erythematosus and antiphospholipid syndrome: a systematic review. Autoimmun. Rev. 15, 38-49 (2016).

256. Yamaji, K. Immunoadsorption for collagen and rheumatic diseases. Transfus. Apher. Sci. 56, 666-670 (2017)

257. Staudt, A. et al. Immunohistological changes in dilated cardiomyopathy induced by immunoadsorption therapy and subsequent immunoglobulin substitution. Circulation 103, 2681-2686 (2001).

258. US National Library of Medicine. ClinicalTrials.gov https://clinicaltrials.gov/ct2/show/NCT00558584 (2018).
259. Dungen, H. D. et al. $\beta 1$-Adrenoreceptor autoantibodies in heart failure: physiology and therapeutic implications. Circ. Heart Fail. 13, e006155 (2020).

260. Schultheiss, H. P. et al. Betaferon in chronic viral cardiomyopathy (BICC) trial: effects of interferon- $\beta$ treatment in patients with chronic viral cardiomyopathy. Clin. Res. Cardiol. 105, 763-773 (2016).

261. Kuhl, U. et al. Chromosomally integrated human herpesvirus 6 in heart failure: prevalence and treatment. Eur. J. Heart Fail. 17, 9-19 (2015).

262. Tschope, C., Elsanhoury, A., Schlieker, S., Van Linthout, S. \& Kuhl, U. Immunosuppression in inflammatory cardiomyopathy and parvovirus B19 persistence. Eur. J. Heart Fail. 21, 1468-1469 (2019).

263. Ameling, S. et al. Changes of myocardial gene expression and protein composition in patients with dilated cardiomyopathy after immunoadsorption with subsequent immunoglobulin substitution. Basic Res. Cardiol. 111, 53 (2016)

264. McNamara, D. M. et al. Controlled trial of intravenous immune globulin in recent-onset dilated cardiomyopathy. Circulation 103, 2254-2259 (2001).

265. Maisch, B. et al. Treatment of inflammatory dilated cardiomyopathy and (peri)myocarditis with immunosuppression and i.v. immunoglobulins. Herz 29, 624-636 (2004).

266. Sudano, I. et al. Cardiovascular disease in HIV infection. Am. Heart J. 151, 1147-1155 (2006).

267. Baik, S. H. et al. A case of influenza associated fulminant myocarditis successfully treated with intravenous peramivir. Infect. Chemother. 47 272-277 (2015)

268. Ito, N. et al. Influenza A H1 N1 pdm09-associated myocarditis during zanamivir therapy. Pediatr. Int. 57 1172-1174 (2015).

269. Sanders, J. M., Monogue, M. L., Jodlowski, T. Z $\&$ Cutrell, J. B. Pharmacologic treatments for coronavirus disease 2019 (COVID-19): a review. JAMA 323, 1824-1836 (2020).

270. McNamara, D. M. et al. Clinical and demographic predictors of outcomes in recent onset dilated cardiomyopathy: results of the IMAC (Intervention in Myocarditis and Acute Cardiomyopathy)-2 study. J. Am. Coll. Cardiol. 58, 1112-1118 (2011).

271. Mann, D. L. et al. Targeted anticytokine therapy in patients with chronic heart failure: results of the Randomized Etanercept Worldwide Evaluation (RENEWAL). Circulation 109, 1594-1602 (2004).

272. Pinkert, S. et al. Prevention of cardiac dysfunction in acute coxsackievirus B3 cardiomyopathy by inducible expression of a soluble coxsackievirus-adenovirus receptor. Circulation 120, 2358-2366 (2009).

273. Pinkert, S. et al. Early treatment of coxsackievirus B3-infected animals with soluble coxsackievirusadenovirus receptor inhibits development of chronic coxsackievirus B3 cardiomyopathy. Circ. Heart Fail. 12, e005250 (2019)

274. Kraft, L., Erdenesukh, T., Sauter, M., Tschope, C. $\&$ Klingel, K. Blocking the IL-1 $\beta$ signalling pathway prevents chronic viral myocarditis and cardiac remodeling. Basic Res. Cardiol. 114, 11 (2019).

275. Brucato, A et al. Effect of anakinra on recurrent pericarditis among patients with colchicine resistance and corticosteroid dependence: the AIRTRIP randomized clinical trial. JAMA 316, 1906-1912 (2016).

276. Scott, I. C., Hajela, V., Hawkins, P. N. \& Lachmann, H. J. A case series and systematic literature review of anakinra and immunosuppression in idiopathic recurrent pericarditis. J. Cardiol. Cases 4, e93-e97 (2011).

277. Rodriguez-Gonzalez, M., Ruiz-Gonzalez, E. \& Castellano-Martinez, A. Anakinra as rescue therapy for steroid-dependent idiopathic recurrent pericarditis in children: case report and literature review. Cardiol. Young 29, 241-243 (2019)

278. US National Library of Medicine. ClinicalTrials.gov https://clinicaltrials.gov/ct2/show/NCT03018834 (2020).

279. US National Library of Medicine. ClinicalTrials.gov https://clinicaltrials.gov/ct2/show/NCT03737110 (2020).

280. Li, Z., Yue, Y. \& Xiong, S. Distinct Th17 inductions contribute to the gender bias in CVB3-induced myocarditis. Cardiovasc. Pathol. 22, 373-382 (2013)

281. Abou-El-Enein, M., Volk, H. D. \& Reinke, P. Clinical development of cell therapies: setting the stage for academic success. Clin. Pharmacol. Ther. 101, 35-38 (2017).

282. Koch, M. et al. Immunosuppression with an interleukin-2 fusion protein leads to improved LV function in experimental ischemic cardiomyopathy. Int. Immunopharmacol. 10, 207-212 (2010). 
283. Fan, M. Y. et al. Differential roles of IL-2 signaling in developing versus mature Tregs. Cell Rep. 25 , 1204-1213 (2018)

284. Van Linthout, S. et al. Mesenchymal stem cells improve murine acute coxsackievirus B3-induced myocarditis. Eur. Heart J. 32, 2168-2178 (2011).

285. Hare, J. M. et al. Randomized comparison of allogeneic versus autologous mesenchymal stem cells for nonischemic dilated cardiomyopathy: POSEIDONDCM trial. J. Am. Coll. Cardiol. 69, 526-537 (2017).

286. Rieger, A. C. et al. Genetic determinants of responsiveness to mesenchymal stem cell injections in non-ischemic dilated cardiomyopathy. EBioMedicine 48, 377-385 (2019).

287. Tschöpe, C. et al. Modulation of the acute defence reaction by eplerenone prevents cardiac disease progression in viral myocarditis. ESC Heart Fail. https://doi.org/10.1002/ehf2.12887 (2020).

288. Lee, W. S. et al. Cannabidiol limits T cell-mediated chronic autoimmune myocarditis: implications to autoimmune disorders and organ transplantation Mol. Med. 22, 136-146 (2016).

289. Branchereau, M., Burcelin, R. \& Heymes, C. The gut microbiome and heart failure: a better gut for a better heart. Rev. Endocr. Metab. Disord. 20, 407-414 (2019).

290. Lorusso, R. et al. Venoarterial extracorporeal membrane oxygenation for acute fulminant myocarditis in adult patients: a 5-year multi-institutional experience. Ann. Thorac. Surg. 101, 919-926 (2016).

291. Kapur, N. K., Davila, C. D. \& Jumean, M. F. Integrating interventional cardiology and heart failure managemen for cardiogenic shock. Interv. Cardiol. Clin. 6, 481-485 (2017).

292. Li, S. et al. A life support-based comprehensive treatment regimen dramatically lowers the in-hospital mortality of patients with fulminant myocarditis: a multiple center study. Sci. China Life Sci. 62, 369-380 (2019).

293. Kapur, N. K. et al. Mechanical circulatory support devices for acute right ventricular failure. Circulation 136, 314-326 (2017).

294. Annamalai, S. K. et al. The Impella microaxial flow catheter is safe and effective for treatment of myocarditis complicated by cardiogenic shock: an analysis from the global CVAD registry. J. Card. Fail. 24, 706-710 (2018).

295. Spillmann, F. et al. Mode-of-action of the PROPELLA concept in fulminant myocarditis. Eur. Heart J. 40, 2164-2169 (2019)
296. Sun, M. et al. Experimental right ventricular hypertension induces regional $\beta 1$-integrin-mediated transduction of hypertrophic and profibrotic right and left ventricular signaling. J. Am. Heart Assoc. 7, e007928 (2018)

297. Lindner, D. et al. Cardiac fibroblasts support cardiac inflammation in heart failure. Basic Res. Cardiol. 109 428 (2014).

298. Levin, H. R. et al. Reversal of chronic ventricular dilation in patients with end-stage cardiomyopathy by prolonged mechanical unloading. Circulation 91 2717-2720 (1995).

299. Hata, J. A. et al. Lymphocyte levels of GRK2 ( $\beta A R K 1)$ mirror changes in the LVAD-supported failing human heart: lower GRK2 associated with improved $\beta$-adrenergic signaling after mechanical unloading. J. Card. Fail. 12, 360-368 (2006)

300. Tschope, C. et al. Mechanical unloading by fulminant myocarditis: LV-IMPELLA, ECMELLA, BI-PELLA, and PROPELLA concepts. J. Cardiovasc. Transl. Res. 12 116-123 (2019).

301. Chaparro, S. V. et al. Combined use of Impella left ventricular assist device and extracorporeal membrane oxygenation as a bridge to recovery in fulminant myocarditis. ASAIO J. 58, 285-287 (2012).

302. Pappalardo, F. et al. Concomitant implantation of Impella((R)) on top of veno-arterial extracorporeal membrane oxygenation may improve survival of patients with cardiogenic shock. Eur. J. Heart Fail. 19, 404-412 (2017)

303. Pappalardo, F., Scandroglio, A. M. \& Latib, A. Full percutaneous biventricular support with two Impella pumps: the Bi-Pella approach. ESC Heart Fail. 5, 368-371 (2018)

304. Fiedler, A. Uber akute interstitielle Myokarditis. Zentralblatt für Innere Med. 21, 212-213 (1900).

305. Sakakibara, S. \& Konno, S. Endomyocardial biopsy. Jpn. Heart J. 3, 537-543 (1962).

306. Zanatta, A., Carturan, E., Rizzo, S., Basso, C. \& Thiene, G. Story telling of myocarditis. Int. J. Cardiol. 294, 61-64 (2019).

307. Ammirati, E., Sormani, P., Moroni, F., Camici, P. C. $\&$ Pedrotti, P. Changes of late gadolinium enhancement extension compared with native T1 mapping early after acute myocarditis. Int. J. Cardiol. 257, 227 (2018)

308. Schultz, J. C., Hilliard, A. A., Cooper, L. T. Jr. $\&$ Rihal, C. S. Diagnosis and treatment of viral myocarditis. Mayo Clin. Proc. 84, 1001-1009 (2009).

\section{Acknowledgements}

C.T. acknowledges the support of the Federal Ministry of Education and Research (BMBF), Germany, for the CaPACITY (Cortisone in Parvovirus Inflammatory Cardiomyopathy) programme. A.L.P.C. acknowledges the support of Budget Integrato per la Ricerca dei Dipartimenti (BIRD, year 2019), Padova University, Padova, Italy (project title: Myocarditis: Genetic Background, Predictors of Dismal Prognosis and of Response to Immunosuppressive Therapy). S.H. acknowledges the support of the ERA-Net-CVD project MacroERA (01KL1706) and IMI2-CARDIATEAM (no. 821508); the support of the Netherlands Cardiovascular Research Initiative, an initiative with support of the Dutch Heart Foundation, CVON2016-Early HFPEF, 2015-10, CVON She-PREDICTS, grant 2017-21, CVON Arena-PRIME, 2017-18; and the support of the Flemish FWO G091018N and FWO G0B5930N. C.T. and S.V.L. acknowledge the support of the German Centre for Cardiovascular Research (DZHK) for the 'Voltage-mapping-guided and MRI-guided endomyocardial biopsy in myocarditis and DCMi' study.

\section{Author contributions}

C.T., N.H., H.M., K.K. and S.V.L. researched data for the article; C.T., E.A., K.K. and S.V.L. contributed to discussion of the content; C.T., E.A., B.B., A.L.P.C., L.T.C, S.B.F., J.M.H., B.H., S.H., S.K., K.K., H.M., A.S.P., F.S., R.C.S., H.T., P.S. and S.V.L. wrote the article and C.T. A.L.P.C. L.T. S.B.F, J.M.H., B.H. S.H. N.H., K.K. and S.V.L. reviewed and/or edited the article before submission

\section{Competing interests}

C.T. is a consultant for Cardiotropic Labs, Miami, FL, USA S.B.F. reports grants from Fresenius Medical Care and ENDI Foundation. J.M.H. holds equity in Heart Genomics. J.M.H. and B.H. are both inventors on a patent involving the use of RNA as a biomarker for myocarditis. The other authors declare no competing interests.

\section{Peer review information}

Nature Reviews Cardiology thanks D. Cihakova, D. Fairweather, A. Frustaci, G. Thiene and the other, anonymous, reviewer(s) for their contribution to the peer review of this work.

\section{Publisher's note}

Springer Nature remains neutral with regard to jurisdictional claims in published maps and institutional affiliations.

(c) Springer Nature Limited 2020 